\title{
PROTECCIÓN AMBIENTAL EN LOS MECANISMOS DE APOYO FINANCIERO A LA GENER ACIÓN DE ENERGÍA VERDE Y EL DERECHO DE LA UNIÓN EUROPEA, EL ASUNTO ÅLANDS VINDKRAFT*
}

\author{
ENVIRONMENTAL PROTECTION FROM \\ FINANCIAL SUPPORT MECHANISMS \\ FOR THE GENERATION OF GREEN \\ ENERGY, AND EUROPEAN UNION LAW, \\ THE ÅANDS VINDKRAFT CASE
}

\author{
José Hernán Muriel-Ciceri**
}

Fecha de recepción: 24 de junio de 2017

Fecha de aceptación: 15 de julio de 2017 Disponibilidad en línea: 30 de noviembre de 2017

\section{Para citar este artículo / To cite this article}

Muriel-Ciceri, José Hernán, Protección ambiental en los mecanismos de apoyo financiero a la generación de energía verde y el derecho de la unión europea, el asunto Alands Vindkraft, 31 International Law, Revista Colombiana de Derecho Internacional, 115-160 (2017). https://doi.org/10.11144/ Javeriana.il15-31.pama

doi:10.11144/Javeriana.i115-31.pama

* Este artículo es resultado de la investigación del Grupo de Investigación en Derecho Económico en la línea en derecho financiero y ambiental de la Facultad de Ciencias Jurídicas de la Pontificia Universidad Javeriana.

** Doctor juris y Legum Magister, Universidad de Konstanz, Alemania. Especialista en derecho administrativo y abogado, Universidad Santo Tomás de Bogotá. Alumnus del Katholischer Akademischer Ausländer-Dienst, KAAD. Profesor del departamento de Derecho Económico y miembro del grupo de investigación en derecho económico, Facultad de Ciencias Jurídicas, Pontificia Universidad Javeriana. Contacto: jh-murielc@javeriana.edu.co 


\section{RESUMEN}

La protección del medio ambiente y la consolidación del desarrollo sostenible en el mercado son simultáneamente realizables y constituyen parte de la cimentación del derecho europeo. Este derecho resalta su viabilidad, en el ámbito de los mecanismos financieros de apoyo a la producción de energía renovable como acciones frente al cambio climático. La armonía de estos mecanismos, previstos, por ejemplo, en la Directiva 2009/28/ CE y su adopción por los Estados miembro de la Unión Europea con la libre circulación de mercancías, es analizada por el Tribunal de Justicia en el asunto Alands Vindkraft AB contra Energimyndigheten (C-573/12). El Tribunal resalta en este caso, el cómo la compatibilidad del clima, la producción de energía verde y el desarrollo del mercado son una necesidad. En este ámbito, la Comisión Europea plantea al Parlamento y al Consejo, un marco de trabajo y un paquete de medidas, que conjuntamente desde sus funciones, concretarán en concordancia con los postulados del derecho europeo.

Palabras clave: Energía verde; sistemas de apoyo a la producción de electricidad verde; certificados verdes; medidas de cooperación; derecho europeo; libertad de circulación de mercancías; relación de cooperación judicial; equilibrio de mercado; principio de proporcionalidad; Ålands Vindkraft 


\begin{abstract}
The protection of the environment and the consolidation of sustainable development in the market are simultaneously achievable, and constitute part of the foundation of European law. This law highlights their viability, in the area of financial mechanisms that support the production of renewable energy in an effort to address climate change. The harmony of thesemechanisms, provided, for example, in Directive 2009/28/EC and its adoption by the Member States of the European Union with the free movement of goods, is analyzed by the Court of Justice in the case of Alands Vindkraft AB v. Energimyndigheten (C-573/12). In this case, the Court highlighted how compatibility among the climate, green energy production and the development of the market is a necessity. In this area, the European Commission has proposed to the Parliament and the Council a framework and package of measures, which they will implement together, based on their functions, in accordance with the provisions of European law.
\end{abstract}

Keywords: Green electricity; support schemes for green electricity production; green certificates; measures of cooperation; European Union Law; freemovement of goods; market balance; principle of proportionality; Alands Vindkraft

\title{
SUMARIO
}

Introducción.- I. El ASunto ÅlandS VINDKRAFT(C-573/12).- A. Hechos.- B. Alegatos de conclusión del abogado general.- II. EXAMEN DE LA EXISTENCIA DE vULNERACIÓn A LA LIBRE CIRCULACIÓN DE MERCANCíAS. - $A$. Ámbito de protección.- 1. Libre circulación de mercancías.-2. La energía como mercancía en el mercado europeo.- 3. Una situación transfronteriza.- B. Restricción a la libre circulación de mercancías.- 1. La Directiva 2009/28/CE.-2. ¿Aplicación de derecho primario?- III. Vigencia DEl ARTículo 3.3 Directiva 2009/28/ CE.- IV. LA PROPuEsta de la COMisión EuRopea 2020-2030 y dE MEdidAs DE ENERgía limpia EN Europa.- ConClusiones.- Bibliografía. 
El derecho ambiental se dirige a la protección de la vida y la salud de los seres humanos, los animales, las plantas y los necesarios fundamentos de la vida'. En el ámbito del derecho europeo, la protección ambiental ${ }^{2}$ está garantizada por medio de su derecho primario u originario ${ }^{3}$ y secundario o derivado ${ }^{4}$. En palabras de Rüdiger Breuer, esta protección es un principio jurídico político anclado en el derecho europeo ${ }^{5}$, reflejado en el contenido del Tratado de la Unión Europea, TUE (preámbulo; artículo 3.3, frase 2; artículo 21.2, d, f) y de su Funcionamiento, TFUE (artículos 11, 4.2, literal e, 114.3, 191-193) y en la Carta de los Derechos Fundamentales de la Unión Europea (artículo 37).

El Tratado de la Unión Europea, TUE, al referirse a la constitución de un mercado interior, establece de forma clara que en este ámbito la Unión deberá actuar en beneficio del desarrollo

1 Cf. Rolf Schwartmann \& Heinz-Joachim Pabst, Umweltrecht, 1 (C.F. Müller, Heidelberg, 2011).

2 Cf. Rüdiger Breuer, Umweltschutzrecht, en Besonderes Verwaltungsrecht, 551-774, 592 (13 ${ }^{\mathrm{a}}$ ed., Eberhard Schmidt-Aßmann \& Peter Badura, eds., Berlin, New York, Gruyter Lehrbuch, 2005).

3 El derecho primario está conformado por los tratados internacionales fundacionales de la Unión: el Tratado de la Unión Europea (TUE), el Tratado de Funcionamiento de la Unión Europea (TFUE) [Cf. Unión Europea, Versión consolidada del Tratado de Funcionamiento de la Unión Europea, C 83/47 Diario Oficial de la Unión Europea, 30 de marzo de 2010. Disponible en: https://www.boe.es/doue/2010/083/Z00047-00199.pdf] y por el Tratado de la Comunidad Europea Atómica (Euratom) [Cf. Unión Europea, Versión consolidada del Tratado constitutivo de la Comunidad Europea de la Energía Atómica, así como sus Anexos y Protocolos Luxemburgo, Oficina de Publicaciones de la Unión Europea (2010). doi:10.2860/52347. Disponible en: https://europa.eu/european-union/sites/europaeu/files/docs/body/consolidated_version of_the_treaty_establishing_the_european_atomic_energy_community_es.pdf], la Carta de los Derechos Fundamentales de la Unión Europea [Cf. Unión Europea, Carta Europea de los Derechos Fundamentales de la Unión Europea (2000/C 364/01), C 364/01 Diario Oficial de las Comunidades Europeas, 18 de diciembre de 2000. Disponible en: http://www.europarl.europa. eu/charter/pdf/text_es.pdf], los principios generales del derecho y el derecho consuetudinario [Cf. Walter Frenz, Europarecht, 1 (Springer-Verlag, Berlin, Heidelberg, 2016). José Hernán Muriel-Ciceri, Die Übertragung der Abfallentsorgung auf Dritte, 163 (Hartung-Gorre Verlag, Konstanz, 2006)].

4 El derecho secundario está constituido por los actos jurídicos proferidos por los órganos de la Unión con base en los Tratados fundacionales, tales como: Reglamentos, Directivas, Decisiones, Recomendaciones y Dictámenes (TFUE, art. 288). Cf. Hans-Wolfgang Arndt, Kristian Fischer \& Thomas Fetzer, Europarecht, 45 (C.F. Müller, Heidelberg, 2015). José Hernán Muriel-Ciceri, Die Übertragung der Abfallentsorgung auf Dritte, 163 (Hartung-Gorre Verlag, Konstanz, 2006).

5 Cf. Rüdiger Breuer, Umweltschutzrecht, en Besonderes Verwaltungsrecht, 551-774, 559 (13 ed., Eberhard Schmidt-Aßmann \& Peter Badura, eds., Berlin, New York, Gruyter Lehrbuch, 2005). 
sostenible con un "nivel elevado de protección y mejora de la calidad del medio ambiente" (artículo 3.3). Concordantemente, el Tratado de Funcionamiento de la Unión Europea, TFUE, determina que la protección del medio ambiente debe "integrarse en la definición y en la realización de las políticas y acciones de la Unión", para el fomento del desarrollo sostenible (artículo 11). Igualmente, la garantía de la protección ambiental es una competencia compartida de la Unión y los Estados miembros (artículo 4.2, e), que de forma especial está regulada para el Parlamento y el Consejo Europeo (artículo 192), sin perjuicio de aquellas medidas de mayor protección, que cada Estado miembro pueda adoptar (artículo 193). Armónicamente, el artículo 114.3 del TFUE precisa que en sus propuestas de aproximación de las legislaciones de la Unión en materia de protección del medio ambiente, la Comisión deberá basarse en un nivel de protección elevado teniendo en cuenta especialmente cualquier novedad que se desprenda de hechos científicos y lo prevé como un objetivo común en el ámbito de sus competencias, con el Parlamento y el Consejo.

Así, la política de la Unión Europea debe contribuir a "-la conservación, la protección y la mejora de la calidad del medio ambiente, - la protección de la salud de las personas, - la utilización prudente y racional de los recursos naturales, - el fomento de medidas a escala internacional destinadas a hacer frente a los problemas regionales o mundiales del medio ambiente y en particular a luchar contra el cambio climático" (artículo 191 TFUE). Al mismo tiempo, la Carta de los Derechos Fundamentales de la Unión Europea fija que las políticas de la Unión deben integrar y garantizar, en consideración al "principio de desarrollo sostenible un alto nivel de protección del medio ambiente y la mejora de su calidad".

En particular, en materia de la política energética de la Unión, el artículo 194 del TFUE se refiere a que esta, en el ámbito del establecimiento o funcionamiento del mercado interior, debe atender a la preservación y mejoramiento del medio ambiente y tiene como uno de sus objetivos el fomento de "la eficiencia 
energética y el ahorro energético así como el desarrollo de energías nuevas y renovables [...]" (artículo 194, c) ${ }^{6}$. Adicionalmente, el artículo 192.2c TFUE establece la competencia del Consejo Europeo para adoptar las medidas "que afecten de forma significativa a la elección por un Estado miembro entre diferentes fuentes de energía y a la estructura general de su abastecimiento energético".

En el derecho secundario, la Directiva 2009/28/CE respecto a las metas de reducción de emisiones de gases de efecto invernadero y al cumplimiento de instrumentos jurídicos comunitarios e internacionales, y al abastecimiento energético y al desarrollo sostenible 7 , adoptó entre otros aspectos, "un marco común para el fomento en los Estados miembro de la Unión, de la energía procedente de fuentes renovables" (artículo 1). Al mismo tiempo estableció como objetivo de cada Estado, velar por que su cuota de energía que procede de fuentes renovables, sea coherente con "un $20 \%$ como mínimo de energía procedente de fuentes renovables en el consumo final bruto de energía de la Comunidad para 2020" (artículo 3.1) ${ }^{8}$. La Directiva autoriza que para el cumplimiento de estas metas, los Estados miembros establezcan medidas como "sistemas de apoyo" y "mecanismos de cooperación entre distintos Estados miembros y con terceros países" (artículo 3.3, a, b). Lo anterior genera un campo jurídico de tensión entre la adopción de las medidas por los Estados miembros y la libertad fundamental de la Unión Europea de circulación de mercancías (artículos 26.2, 28 a 39 TFUE $^{9}$ ). De

6 La energía es un elemento esencial en el desarrollo de la humanidad y de la armonía con su entorno. En este ámbito, Dietrich Pelte se formula la pregunta de ¿cómo se ve el futuro de nuestro abastecimiento energético?, la cual estudia desde la perspectiva de la física y la economía. Cf. Dietrich Pelte, Die Zukunft unserer Energieversorgung. Eine Analyse aus mathematisch-naturwissenschaftlicher Sicht, v (Springer-Verlag, Wiesbaden, 2014). Esta temática tiene además relevancia jurídica y es atendida de forma considerable en el derecho europeo.

7 Cf. Parlamento Europeo y Consejo Europeo, Directiva 2009/28/CE, de 23 de abril de 2009, relativa al fomento del uso de energía procedente de fuentes renovables y por la que se modifican y se derogan las Directivas 2001/77/CE y 2003/30/CE (Texto pertinente a efectos del EEE), L 140/16 Diario Oficial de la Unión Europea, 5 de junio de 2009, Considerando 1. Disponible en: https://www.boe.es/doue/2009/140/L00016-00062.pdf

8 Cf. Markus Ludwigs, Grenzen für eine nationale Energiepolitik im EU-Binnenmarkt, 11 Zeitschrift für das gesamte Energiewirtschaftsrecht, EnWZ, 483-488, 483 (2013).

9 La libre circulación de mercancías (i) es garantizada por el derecho europeo como una de las 
ello surge, además, la pregunta sobre la armonía de tales medidas con el derecho europeo.

Metodológicamente, el presente estudio se ocupa de esta materia, desde el análisis central de la posición adoptada en una decisión prejudicial por parte del Tribunal de Justicia Europeo, en el asunto Alands Vindkraft AB contra Energimyndigheten (C$573 / 12)^{10}$, teniendo presente en especial el examen de la compatibilidad del contenido correspondiente de la Directiva 2009/28/ $\mathrm{CE}$ ["relativa al fomento del uso de energía procedente de fuentes renovables y por la que se modifican y se derogan las Directivas 2001/77/CE y 2003/30/CE"] con la normatividad del derecho europeo primario y su desarrollo jurisprudencial, así como la propuesta de la Comisión Europea de adopción de medidas para el fomento de energía verde en Europa. Lo anterior, con la finalidad de que el presente artículo de investigación pueda aportar a la comprensión de uno de los elementos del derecho europeo ambiental.

Consecuentemente, el artículo se organiza en cuatro partes: primero se consideran los hechos del caso y los alegatos de conclusión del abogado general (I). A continuación, se examina la existencia de una vulneración a la garantía europea de la libre circulación de mercancías (II). Posteriormente, se evalúa la vigencia de la Directiva 2009/28/CE (III) así como la propuesta de la Comisión Europea de un marco estratégico en materia de clima y energía para el período 2020-2030 y de medidas de fomento de la energía renovable en Europa (IV). Con base en ello, se desarrollan las conclusiones.

cuatro libertades fundamentales de la Unión Europea, conjuntamente con la libre circulación de trabajadores (ii), la libertad de establecimiento y libre prestación de servicios (iii) y la libre circulación de capitales (iv). Cf. Parlamento Europeo, Fichas técnicas sobre la Unión Europea, El mercado interior, 3.1. El mercado interior: marco general. Disponible en: http://www. europarl.europa.eu/atyourservice/es/displayFtu.html?ftuId=theme3.html. Kay Hailbronner \& Georg Jochum, Europarecht II, Binnenmarkt und Grundfreiheiten, 1 (Verlag W. Kohlhammer GmbH, Stuttgart, 2006). Christian Koenig \& Andreas Haratsch, Europarecht, 197 y ss. (4a ed., J. C. B. Mohr Paul Siebeck, Tübingen, 2003).

10 Cf. Unión Europea, Tribunal de Justicia (gran sala), sentencia de 1 de julio de 2014, asunto C-573/12, Ålands Vindkraft AB contra Energimyndigheten, Petición de decisión prejudicial: Förvaltningsrätten i Linköping - Suecia. Disponible en: http://curia.europa.eu/juris/liste. jsf?language $=$ es\&num $=\mathrm{C}-573 / 12$ 


\section{El ASUNTO ÅlANDS VINDKRAFT (C-573/12)}

A. Hechos

En 2009, la empresa Ålands Vindkraft AB solicitó ante la autoridad sueca competente la homologación de su parque eólico ${ }^{11}$, ubicado en el archipiélago de las islas Åland en Finlandia, con el propósito de obtener certificados verdes. Estos constituyen instrumentos negociables en un mercado abierto a la competencia, donde el precio es establecido por la oferta y la demanda ${ }^{12}, y$ son concedidos por disposición legal de 2011, a los productores de electricidad generada con fuentes renovables (electricidad verde $)^{13}$, producida en el territorio sueco ${ }^{14}$. Los productores de esta clase de electricidad reciben mediante la venta de los certificados verdes "un ingreso adicional como rendimiento complementario por su producción de electricidad"15.

En concreto, la ley sueca instituye un sistema de certificados verdes que obliga a los proveedores de electricidad ${ }^{16}$ y a determinados consumidores de esta, a adquirir un número de certificados que correspondan a cierta parte de sus ventas y

11 "Un parque eólico de generación eléctrica consiste en una serie de instalaciones que transforman la energía cinética del flujo del viento en energía eléctrica". Antonio Aguilera-Nieves, Gestión del mantenimiento de instalaciones de energía eólica, 7 (Editorial Vértice, Málaga, 2012). Respecto al análisis de la energía eólica, la protección de especies y los intereses del derecho de propiedad, y la correspondiente aplicabilidad de la evaluación del impacto ambiental, Walter Frenz, Windkraft vs. Artenschutz und Eigentümerbelange, 38 Natur und Recht, NuR, 4, 251-257 (2016).

12 Cf. Unión Europea, Tribunal de Justicia (gran sala), sentencia de 1 de julio de 2014, asunto C-573/12, Ålands Vindkraft AB contra Energimyndigheten, Petición de decisión prejudicial: Förvaltningsrätten i Linköping - Suecia, apartado 15.

13 Cf. Antonio Baena \& Ana Pueyo, Competitividad y cambio climático: nuevos retos para la industria española (Colección EOI Medio Ambiente, EOI Escuela de Organización Industrial, España, 2007). Disponible en: https://www.eoi.es/es/savia/publicaciones/20596/competitividady-cambio-climatico-nuevos-retos-para-la-industria-espanola

14 Cf. Unión Europea, Tribunal de Justicia (gran sala), sentencia de 1 de julio de 2014, asunto C-573/12, Ålands Vindkraft AB contra Energimyndigheten, Petición de decisión prejudicial: Förvaltningsrätten i Linköping - Suecia, apartado 38.

15 Cf. Unión Europea, Tribunal de Justicia (gran sala), sentencia de 1 de julio de 2014, asunto C-573/12, Ålands Vindkraft AB contra Energimyndigheten, Petición de decisión prejudicial: Förvaltningsrätten i Linköping - Suecia, apartado 32.

16 El proveedor repercute el precio de compra de los certificados eléctricos en el consumidor, cf. Unión Europea, Tribunal de Justicia (gran sala), sentencia de 1 de julio de 2014, asunto C-573/12, Alands Vindkraft AB contra Energimyndigheten, Petición de decisión prejudicial: Förvaltningsrätten i Linköping - Suecia, apartado 18. 
consumo en ese país, sin que haya una obligación correlativa a la compra de energía de esa misma fuente ${ }^{17}$ así como la obligación adicional "de entregar anualmente", cada 1 de abrill , "a la autoridad competente un número determinado de tales certificados" correspondiente a una parte de la totalidad de sus suministros o uso de la electricidad ${ }^{19}$. En el evento de que los obligados no entreguen el número de instrumentos verdes establecido en esa fecha, se les impone "el pago de una cantidad de dinero", denominado "derecho específico" ${ }^{20}$. Tal obligación se extiende a los proveedores y consumidores que importen electricidad ${ }^{21}$. Adicionalmente, en armonía con el artículo 11 de la Directiva 2009/28/CE ${ }^{22}$, la ley sueca establece que los certificados verdes otorgados por la producción en otro Estado pueden utilizarse para cumplir la cuota de ese país, pero exige un acuerdo internacional con el otro Estado. Al momento de los hechos, no había un tratado sobre la materia entre el Reino de Suecia y la República de Finlandia ${ }^{23}$; por el contrario, sí hay un tratado correspondiente con el Reino de Noruega ${ }^{24}$.

17 Cf. Unión Europea, Tribunal de Justicia (gran sala), sentencia de 1 de julio de 2014, asunto C-573/12, Ålands Vindkraft AB contra Energimyndigheten, Petición de decisión prejudicial: Förvaltningsrätten i Linköping - Suecia, apartado 32.

18 Cf. Unión Europea, Tribunal de Justicia (gran sala), sentencia de 1 de julio de 2014, asunto C-573/12, Allands Vindkraft AB contra Energimyndigheten, Petición de decisión prejudicial: Förvaltningsrätten i Linköping - Suecia, apartado 15.

19 Cf. Unión Europea, Tribunal de Justicia (gran sala), sentencia de 1 de julio de 2014, asunto C-573/12, Ålands Vindkraft AB contra Energimyndigheten, Petición de decisión prejudicial: Förvaltningsrätten i Linköping - Suecia, apartado 54.

20 Cf. Unión Europea, Tribunal de Justicia (gran sala), sentencia de 1 de julio de 2014, asunto C-573/12, Alands Vindkraft AB contra Energimyndigheten, Petición de decisión prejudicial: Förvaltningsrätten i Linköping - Suecia, apartados 19, 55, 69.

21 Cf. Unión Europea, Tribunal de Justicia (gran sala), sentencia de 1 de julio de 2014, asunto C-573/12, Alands Vindkraft AB contra Energimyndigheten, Petición de decisión prejudicial: Förvaltningsrätten i Linköping - Suecia, apartado 69.

22 Cf. Parlamento Europeo y Consejo Europeo, Directiva 2009/28/CE, de 23 de abril de 2009, relativa al fomento del uso de energía procedente de fuentes renovables y por la que se modifican y se derogan las Directivas 2001/77/CE y 2003/30/CE (Texto pertinente a efectos del EEE), L 140/16 Diario Oficial de la Unión Europea, 5 de junio de 2009.

23 Cf. Unión Europea, Tribunal de Justicia (gran sala), sentencia de 1 de julio de 2014, asunto C-573/12, Ålands Vindkraft AB contra Energimyndigheten, Petición de decisión prejudicial: Förvaltningsrätten i Linköping - Suecia, apartados 20-22.

24 Cf. Unión Europea, Tribunal de Justicia (gran sala), sentencia de 1 de julio de 2014, asunto C-573/12, Ålands Vindkraft AB contra Energimyndigheten, Petición de decisión prejudicial: Förvaltningsrätten i Linköping - Suecia, apartado 101. 
La solicitud de homologación presentada por Alands Vindkraft AB fue objetada por la autoridad competente en 2010, por considerar que ante el derecho sueco, únicamente son homologables aquellas instalaciones de producción eléctrica ubicadas en ese mismo país ${ }^{25}$. Frente a la decisión, la empresa presentó un recurso judicial ante el Tribunal Contencioso Administrativo de Linköping dirigido a la anulación de la decisión $\mathrm{y}$ al otorgamiento de la solicitud ${ }^{26}$. En consecuencia, el Tribunal suspendió el procedimiento y planteó cuestiones prejudiciales ante el Tribunal de Justicia Europeo ${ }^{27}$, correspondientes a si los artículos 2, II, k y 3.3 de la Directiva 2009/28/CE permiten el establecimiento por un Estado miembro de un sistema interno de apoyo $^{28}$. Estas cuestiones hacen referencia a si el sistema

25 Cf. Unión Europea, Tribunal de Justicia (gran sala), sentencia de 1 de julio de 2014, asunto C-573/12, Alands Vindkraft AB contra Energimyndigheten, Petición de decisión prejudicial: Förvaltningsrätten i Linköping - Suecia, apartado 24.

26 Cf. Unión Europea, Tribunal de Justicia (gran sala), sentencia de 1 de julio de 2014, asunto C-573/12, Alands Vindkraft AB contra Energimyndigheten, Petición de decisión prejudicial: Förvaltningsrätten i Linköping - Suecia, apartado 25. Guido Wustlich, Das Erneuerbare-Energien-Gesetz 2014: Grundlegend neu - aber auch grundlegend anders?, 17 Neue Zeitschrift für Verwaltungsrecht, $N V w Z, 1113-1122,1114$ (2014). Boris Scholtka \& Antje Baumbach, Die Entwicklung des Energierechts im Jahr 2014, 13 Die Neue Juristische Wochenschrift,, NJW, 911-916, 915 (2015). Armin Steinbach, Renewable Energy and the Free Movement of Goods, 1-20, 19 (Nuffield College Working Paper Series in Politics, Robert Brückmann Head, Policy Department, Eclareon, 2015). Disponible en: https://www.nuffield.ox.ac.uk/Research/ Politics\%20Group/Working\%20papers/Documents/Renewable\%20Energy\%20and\%20the\%20 Free\%20Movement\%20of\%20Goods.pdf

27 El Tribunal Europeo de Justicia se compone de dos órganos, el Tribunal de Justicia y el Tribunal General. [Cf. Unión Europea, Información básica sobre la Unión Europea, Instituciones y organismos de la UE, Tribunal de Justicia de la Unión Europea (TJUE). Disponible en: https:// europa.eu/european-union/about-eu/institutions-bodies/court-justice_es]. El Tribunal de Justicia (TJ) es competente para conocer de las cuestiones prejudiciales (artículo 256 TFUE). En virtud de esta facultad, el Tribunal se pronuncia sobre "la interpretación de los Tratados" (a) y "la validez e interpretación de los actos adoptados por las instituciones, órganos u organismos de la Unión" (b) (artículo 265 TFUE). El pronunciamiento de Tribunal sobre un asunto de esta naturaleza se presenta a solicitud de un órgano jurisdiccional de uno de los Estados miembros, cuando este considera necesaria una decisión previa del Tribunal para poder emitir su fallo (artículo 267.2 TFUE). En el evento de que su decisión no sea susceptible "de ulterior recurso judicial de Derecho interno, dicho órgano estará obligado a someter la cuestión al Tribunal" (artículo 267.3 TFUE). En el sentido de Koenig y Haratsch, esta competencia tiene como finalidad evitar que "un Estado miembro desarrolle una jurisprudencia que no esté en armonía con el derecho" de la Unión Europea y genera a la vez una "relación de cooperación" procesal entre el TJUE y los tribunales judiciales de los Estados miembros [cf. Christian Koenig \& Andreas Haratsch, Europarecht, 152 (4 $4^{\mathrm{a}}$ ed., J. C. B. Mohr Paul Siebeck, Tübingen, 2003)]. El caso Alands Vindkraft fue resuelto con base en la competencia del Tribunal de Justicia de resolver la petición de decisión prejudicial planteada por el Tribunal sueco de Linköping.

28 Un sistema de apoyo “....al que solo pueden acogerse los productores situados geográficamente dentro del territorio nacional y que implica que se favorezca económicamente a dichos pro- 
analizado constituye en el ámbito del artículo 34 del TFUE, "una restricción cuantitativa a la importación o una medida de efecto equivalente", y si ello es compatible con el contenido de esta disposición (i), al considerar que el objetivo de la medida es el fomento de "la producción de electricidad [verde]" (ii) así como que la limitación de tal sistema no está regulada de forma expresa en el derecho interno sueco (iii).

\section{B. Alegatos de conclusión del abogado general}

En los alegatos de conclusión que presentó ante el Tribunal en enero de 2014, el abogado general Bot indicó que los artículos 2, II, k y 3.3 de la Directiva 2009/28/CE deben interpretarse en el sentido de que, por una parte, el sistema nacional de apoyo a la energía renovable establece una obligación de cuota y que, además, la Directiva autoriza a los Estados miembros a establecer estos mecanismos con una reserva de concesión de los certificados verdes a las instalaciones localizadas en su territorio. Ello - considera el abogado general - es contrario al contenido del artículo 34 TFUE $^{29}$. Por lo anterior, propone al Tribunal de Justicia la declaratoria de oficio de la invalidez del artículo 3.3 de la Directiva 2009/28/CE y diferir los efectos de la decisión a "dos años después del pronunciamiento de la sentencia"30. Estos alegatos fundamentan la declaratoria de invalidez en la jurisprudencia del Tribunal y su aplicación al ámbito de competencia del artículo 267 TFUE, en el sentido de que cuando el Tribunal de Justicia, establezca la razón de ser de las cuestiones planteadas en "[...] el examen de la validez más que la interpretación de los

ductores en relación con los productores a los que no pueden concederse certificados eléctricos". Unión Europea, Tribunal de Justicia (gran sala), sentencia de 1 de julio de 2014, asunto C-573/12, Ålands Vindkraft AB contra Energimyndigheten, Petición de decisión prejudicial: Förvaltningsrätten i Linköping - Suecia, apartado 32.

29 Cf. Unión Europea, Tribunal de Justicia, asunto C-573/12, Alands Vindkraft AB contra Energimyndigheten, Conclusiones del Abogado General Yves Bot, presentadas el 28 de enero de 2014, apartado 128. Disponible en: http://eur-lex.europa.eu/legal-content/ES/TXT/?uri=C ELEX\%3A62012CC0573\#Footnote30

30 Cf. Unión Europea, Tribunal de Justicia, asunto C-573/12, Alands Vindkraft AB contra Energimyndigheten, Conclusiones del Abogado General Yves Bot, presentadas el 28 de enero de 2014, apartado 128. 
actos [de la Unión], el Tribunal de Justicia debe pronunciarse de inmediato, sin imponer a dicho órgano jurisdiccional un formalismo puramente dilatorio incompatible con la naturaleza propia de los mecanismos creados por el artículo" 267 TFUE $^{31}$. Concordantemente, el abogado general considera que el contenido del artículo 3.3 de la Directiva 2009/28/CE como disposición de derecho derivado, es incompatible con el contenido del artículo 34 TFUE en su carácter de disposición de derecho primario y por ello debe ser declarada su invalidez ${ }^{32}{ }^{33}$.

\section{EXAMEN DE LA LIBERTAD DE CIRCULACIÓN DE MERCANCÍAS}

\section{A. Ámbito de protección}

\section{Libre circulación de mercancías}

La garantía de la libertad de circulación de mercancías en la Unión (artículos 28 a 37 TFUE) es una de las libertades económicas fundamentales ${ }^{34}$ en la liberalización ${ }^{35}$ y realización del mercado interior europeo (artículos $26.2^{36}, 27,114,115$ TFUE) ${ }^{37}$. Como uno de los contenidos principales de esta garantía puede resaltarse la prohibición entre los Estados miembro de restric-

31 Cf. Unión Europea, Tribunal de Justicia, asunto C-573/12, Ålands Vindkraft AB contra Energimyndigheten, Conclusiones del Abogado General Yves Bot, presentadas el 28 de enero de 2014, apartado 67, con remisión: Comunidades Europeas, Tribunal de Justicia, sentencia de 1 de diciembre de 1965, asunto 16/65, C. Schwarze contra Einfuhr- und Vorratsstelle für Getreide und Futtermittel (Schwarze). Disponible en: http://eur-lex.europa.eu/legal-content/ ES/TXT/PDF/?uri=CELEX:61965CJ0016\&from $=$ DE

32 Cf. Unión Europea, Tribunal de Justicia, asunto C-573/12, Alands Vindkraft AB contra Energimyndigheten, Conclusiones del Abogado General Yves Bot, presentadas el 28 de enero de 2014, apartado 72. Respecto al alcance de esta competencia invocada, Bärbel Sachs, Die Ex-officio-Prüfung durch die Gemeinschaftsgerichte, 80 (Mohr Paul Siebeck, Tübingen, 2008).

33 Cf. El análisis de Markus Ludwigs, Die Förderung erneuerbarer Energien im doppelten Zangengriff des Unionsrechts, 06 Europäische Zeitschrift für Wirtschaftsrecht, EuZW, 201-202 (2014).

34 Cf. Ulrich Fastenrath \& Thomas Groh, Europarecht, 63-64 (3ª ed., Boorberg, Stuttgart, 2012).

35 Cf. Ferdinand Wollenschläger, Grundfreiheit ohne Markt. Die Herausbildung der Unionsbürgerschaft im unionsrechtlichen Freizügigkeitsregime, 13 (Mohr Siebeck, Tübingen, 2006).

36 Cf. "El mercado interior implicará un espacio sin fronteras interiores, en el que la libre circulación de mercancías, personas, servicios y capitales estará garantizada de acuerdo con las disposiciones de los Tratados". Artículo 26.2, Tratado de Funcionamiento de la Unión Europea.

37 Cf. Parlamento Europeo, Fichas técnicas sobre la Unión Europea, El mercado interior, 3.1. El mercado interior: marco general. 
ciones cuantitativas (injustificadas) a la importación (artículo 34 TFUE) y exportación (artículo $35 \mathrm{TFUE}^{38}$ ), así como de todas aquellas medidas de efecto equivalente (artículos 34 y 35 TFUE) ${ }^{39}$. No obstante, esta libertad debe armonizarse con los objetivos primordiales de la Unión, tales "como la protección del medio ambiente o la salud humana" ${ }^{\prime 4}$, que pueden generar restricciones o prohibiciones autorizadas por el derecho europeo a la libre circulación de mercancías (artículo 36 TFUE) ${ }^{41}$. Concordantemente, debe analizarse la compatibilidad del mecanismo de apoyo interno sueco a la generación de energía renovable con el contenido del artículo 34 del TFUE.

Lo anterior se diferencia de la libertad de prestación de servicios, regulada en el artículo 57 TFUE, en virtud del cual se considerarán "como servicios" aquellas "prestaciones realizadas

38 El artículo 35 del TFUE establece la prohibición "entre los Estados miembros [de] las restricciones cuantitativas a la exportación, así como todas las medidas de efecto equivalente". En el asunto 15/79 de 1979 (Groenveld), el Tribunal de Justicia estableció respecto al antiguo artículo 34.1 TCEE (correspondiente al artículo 35 del TFUE), que se consideran "restricciones cuantitativas a la exportación las medidas nacionales que tengan por objeto o por efecto restringir específicamente las corrientes de exportación y establecer así una diferencia de trato entre el comercio interior de un Estado miembro y su comercio de exportación, de modo que se proporcione una ventaja especial a la producción nacional o al mercado interior del Estado interesado, en detrimento de la producción o del comercio de otros Estados miembros". Cf. European Court of Justice (second chamber), judgment of 8 November 1979, case 15/79, $P$. B. Groenveld B.V., Haarlem, and Produktschap voor Vee en Vlees [Cattle and Meat Board], Rijswijk, (Groenveld), num. 7. Disponible en: http://curia.europa.eu/juris/showPdf.jsf;jsessio nid=9ea7d2dc30d675728081e2a9453da31d87064073be24.e34KaxiLc3qMb40Rch0SaxyLb3r 0 text $=\&$ docid $=90272 \&$ pageIndex $=0 \&$ doclang $=E N \&$ mode $=1$ st \&dir $=\& o c c=$ first \&part $=1 \& \mathrm{c}$ id $=1019751$

39 Tal como indica la Dirección General de Empresa e Industria de la Comisión Europea, aproximadamente el " $75 \%$ del comercio en el interior de la UE es de mercancías" y el mercado único "ayuda a las empresas de la UE a construir una plataforma fuerte en un entorno abierto, diverso y competitivo". Cf. Unión Europea, Comisión Europea, Dirección C, Política reglamentaria, de la Dirección General de Empresa e Industria, Libre circulación de mercancías, Guía para la aplicación de las disposiciones del Tratado que rigen la libre circulación de mercancías, 8, 26. Disponible en: http://bookshop.europa.eu/es/libre-circulaci-n-de-mercanc-as-pbNB3109160/. Comunidades Europeas, Tribunal de Justicia, sentencia de 15 de diciembre de 1982, asunto 286/81, Oosthoek's Uitgeversmaatschappij BV, apartado 13. Disponible en: http://curia.europa. eu/juris/showPdf.jsf;jsessionid=9ea7d2dc30ddaee992aa639444f2812ae0fc7558bcb1.e34KaxiL c3qMb40Rch0SaxuRbxn0?text=\&docid=91544\&pageIndex $=0 \&$ doclang $=$ es\&mode $=1$ st\&dir $=\&$ occ $=$ first\&part $=1 \&$ cid $=132480$

40 Cf. Unión Europea, Comisión Europea, Dirección C, Política reglamentaria, de la Dirección General de Empresa e Industria, Libre circulación de mercancías, Guía para la aplicación de las disposiciones del Tratado que rigen la libre circulación de mercancías, 8.

41 Cf. Unión Europea, Comisión Europea, Dirección C, Política reglamentaria, de la Dirección General de Empresa e Industria, Libre circulación de mercancías, Guía para la aplicación de las disposiciones del Tratado que rigen la libre circulación de mercancías, 8. 
normalmente a cambio de una remuneración, en la medida en que no se rijan por las disposiciones relativas a la libre circulación de mercancías, capitales y personas". Esta disposición indica como servicios, en particular, “a) actividades de carácter industrial; b) actividades de carácter mercantil; c) actividades artesanales" [y] "d) actividades propias de las profesiones liberales". Como Christian Koenig y Andreas Haratsch aclaran, la libre prestación de servicios es un concepto específico del derecho europeo, en el cual el hecho de que la prestación deba ser una actividad delimita esta libertad, la de la circulación de mercancías analizada aquí ${ }^{42}$.

\section{La energía como mercancía en el mercado europeo}

No hay en el Tratado de la Unión Europea o en el de su Funcionamiento, una definición de mercancía; sin embargo, su conceptualización es necesaria, de modo que, como indican Christian Koenig y Andreas Haratsch, pueda distinguirse la libre circulación de mercancías de la libre prestación de servicios $^{43}$. En 1968, en el asunto $7 / 68^{44}$, el Tribunal de Justicia analizó el contenido del artículo 9 del entonces vigente Tratado Constitutivo de la Comunidad Económica Europea ${ }^{45}$ (TCEE), según el cual, "la Comunidad se basará en una unión aduanera, "que abarcará la totalidad de los intercambios de mercancías"" y consideró como mercancías, "[...] los productos que pueden valorarse en dinero y que, como tales, pueden ser objeto de transacciones comerciales" ${ }^{\prime 4}$. El contenido del artículo 9 del

42 Cf. Christian Koenig \& Andreas Haratsch, Europarecht, 248 (4ª ed., J. C. B. Mohr Paul Siebeck, Tübingen, 2003).

43 Cf. Christian Koenig \& Andreas Haratsch, Europarecht, 152 (4 ed., J. C. B. Mohr Paul Siebeck, Tübingen, 2003).

44 Cf. Comunidades Europeas, Tribunal de Justicia, sentencia 10 de diciembre de 1968, asunto 7/68, Comisión de las Comunidades Europeas contra la República Italiana. Disponible en: $\mathrm{http}: /$ curia.europa.eu/juris/showPdf.jsf?text $=\&$ docid= 87685 \&pageIndex $=0 \&$ doclang $=E S \& m$ ode $=1$ st \&dir $=\&$ occ $=$ first \&part $=1 \&$ cid $=238292$

45 Cf. Comunidad Económica Europea, Tratado Constitutivo de la Comunidad Económica Europea, Roma, 25 de marzo de 1957, artículo 9. Disponible en: http://ocw.uc3m.es/historiadel-derecho/historia-de-la-integracion-europea/tratados/Tratado_Cee.pdf/view

46 Cf. Comunidades Europeas, Tribunal de Justicia, sentencia 10 de diciembre de 1968, asunto 7/68, Comisión de las Comunidades Europeas contra la República Italiana. 
TCEE corresponde al que estaba previsto en el artículo 28.1 del $\mathrm{TFUE}^{47}$. En todo caso, a pesar de la apreciación de carecer la energía eléctrica (posiblemente) de corporalidad, autores como Walter Frenz ${ }^{48}$ y Carola Glinski ${ }^{49}$ resaltan cómo la jurisprudencia del Tribunal de Justicia constantemente le ha dado a la energía el tratamiento de mercancía y aplicación a los preceptos de la libre circulación de mercancías ${ }^{50}$. Esta es, por ejemplo, la posición adoptada por el Tribunal en el caso Almelo, de 1994. En este caso, el Tribunal con base en el TCEE dispuso, que la utilización de los términos "importación" y "exportación" así como "producto", previstos en el artículo 37, permitía deducir que tal norma se refería a "los intercambios de mercancías"; y además resaltó la aceptación común de la electricidad como mercancía en el sentido del artículo 30. Esa disposición se refería en aquel entonces, a la prohibición entre los Estados miembros de las "restricciones cuantitativas a la importación, así como [a] todas las medidas de efecto equivalente". Consecuentemente, tal interpretación es aplicable al contenido del artículo 34 del TFUE así como es la electricidad verde en el mercado europeo, una forma de mercancía.

47 Unión Europea, Versión consolidada del Tratado de Funcionamiento de la Unión Europea, C 83/47 Diario Oficial de la Unión Europea, 30 de marzo de 2010, artículo 28.1. Disponible en: https://www.boe.es/doue/2010/083/Z00047-00199.pdf. "La Unión comprenderá una unión aduanera, que abarcará la totalidad de los intercambios de mercancías y que implicará la prohibición, entre los Estados miembros, de los derechos de aduana de importación y exportación y de cualesquiera exacciones de efecto equivalente, así como la adopción de un arancel aduanero común en sus relaciones con terceros países".

48 Cf. Walter Frenz, Handbuch Europarecht, Band 1, Europäische Grundfreiheiten, 292 (2 ed., Springer, Heidelberg, 2012), con remisión a Unión Europea, Tribunal de Justicia, sentencia 27 de abril de 1994, asunto C-393/92, Gemeente Almelo y otros Energiebedrijf IJsselmij NV (Almelo). Disponible en: http://curia.europa.eu/juris/showPdf.jsf?text $=\&$ docid=98695\&pag eIndex $=0 \&$ doclang $=E S \&$ mode $=1$ st \&dir $=\& o c c=$ first \&part $=1 \& c i d=896345$. Unión Europea, Tribunal de Justicia, sentencia de 13 de marzo de 2001, asunto C-379/98, PreussenElektra AG y Schleswag AG, con intervención de Windpark Reußenköge III GmbH y Land SchleswigHolstein. Disponible en: http://curia.europa.eu/juris/document/document.jsf?text=\&docid=4 5891\&pageIndex $=0$ \&doclang $=E S \&$ mode $=1$ st \&dir $=\&$ occ $=$ first \&part $=1 \&$ cid $=319564$

49 Cf. Carola Glinski, Zu Viel Angst vor dem Europarecht?! Die "Energiewende" Zwischen Nationaler Politikhoheit Und Europäischem Binnenmarkt, 17 Zeitschrift für Europarechtliche Studien, ZEuS, 2, 235-255, 237 (2014).

50 Carola Glinski, Zu Viel Angst vor dem Europarecht?! Die “Energiewende” Zwischen Nationaler Politikhoheit Und Europäischem Binnenmarkt, 17 Zeitschrift für Europarechtliche Studien, ZEuS, 2, 235-255, 237 (2014). 


\section{Una situación transfronteriza}

La libertad de circulación de mercancías garantiza el libre comercio entre los Estados miembros y exige la existencia de una situación transfronteriza frente a otro Estado de la Unión ${ }^{51}$. El caso Ålands Vindkraft se refiere a un intercambio comercial transfronterizo de electricidad verde en la Unión Europea ${ }^{52}$.

\section{B. Restricción a la libre circulación de mercancías}

Antes de analizar si con base en el artículo 34 del TFUE, el mecanismo de apoyo interno sueco a la generación de energía renovable constituye o no una restricción cuantitativa a la importación de la energía, o una medida de efecto equivalente, debe considerarse el contenido y finalidad de la Directiva 2009/28/CE.

\section{La Directiva 2009/28/CE}

La Directiva 2009/28/CE tiene como objeto "establecer un marco común para el fomento de la energía procedente de fuentes renovables". Los considerandos de la Directiva prevén como metas en la Unión Europea, la reducción de gases de efecto invernadero y el cumplimiento de las normas internacionales ${ }^{53}$ en esta materia, lo que permite el crecimiento económico ${ }^{54}$, incrementa las fuentes de ingresos y la creación regional y local

51 Cf. Fastenrath \& Groh resaltan como una excepción, la libre circulación de capitales y de pagos estipulada en el artículo 62.1 del TFUE, en virtud del cual "[...] quedan prohibidas todas las restricciones a los movimientos de capitales entre Estados miembros y entre Estados miembros y terceros países", Ulrich Fastenrath \& Thomas Groh, Europarecht, 63-64 (3ª ed., Boorberg, Stuttgart, 2012). André Lippert, Der grenzüberschreitende Sachverhalt im Unionsrecht: Eine Analyse anhand der Rechtsprechung des Europäischen Gerichtshofs zu den Kontrollkompetenzen, 225 (Mohr Siebeck, Tübingen, 2013).

52 Cf. Unión Europea, Tribunal de Justicia (gran sala), sentencia de 1 de julio de 2014, asunto C-573/12, Ålands Vindkraft AB contra Energimyndigheten, Petición de decisión prejudicial: Förvaltningsrätten i Linköping - Suecia, apartado 86.

53 Cf. Matthias Herdegen, Principles of International Economic Law, 144 (Oxford University, Oxford, 2016).

54 Cf. Parlamento Europeo y Consejo Europeo, Directiva 2009/28/CE, de 23 de abril de 2009, relativa al fomento del uso de energía procedente de fuentes renovables y por la que se modifican y se derogan las Directivas 2001/77/CE y 2003/30/CE (Texto pertinente a efectos del EEE), L 140/16 Diario Oficial de la Unión Europea, 5 de junio de 2009, considerando 1. 
de empleos ${ }^{55}$ con fomento a las pequeñas y medianas empresas, $\mathrm{PYME}^{56}$, y el desarrollo en la Unión ${ }^{57}$, por medio de la "innovación" y de "una política energética competitiva y sostenible" 58 , para una mejora "del $20 \%$ en la eficiencia energética" de la Unión Europea a $2020^{59}$.

En este sentido, la Directiva busca reducir las emisiones de gases de efecto invernadero y la dependencia de las importaciones energéticas, fomentar el desarrollo de energías verdes vinculadas al aumento de la eficiencia energética ${ }^{60}$ e impulsar nuevas tecnologías en el sector energético ${ }^{61}$. A ello se dirige su contenido, sobre la base de alcanzar el objetivo obligatorio establecido por el Consejo Europeo en 2007 “del 20\% de energía procedente de fuentes renovables en el consumo total de energía de la UE en 2020" y del 10\% "con relación al porcentaje de biocarburantes sobre el conjunto de los combustibles (gasóleo y gasolina) de transporte consumidos en 2020", respetando la relación costo-eficacia ${ }^{62}$. Concordantemente, se establecieron como metas de cada Estado miembro, "alcanzar una cuota del $20 \%$ de energía procedente de fuentes renovables en el consumo de energía y una cuota del 10\% de energía procedente de fuentes renovables en el consumo de combustibles para el transporte en la Comunidad para 2020"63. Estos objetivos nacionales buscan brindar seguridad a los inversores en este ámbito y la promoción permanente de tecnologías de generación de energías con fuentes renovables ${ }^{64}$. Con esta finalidad, los Estados miembros deben establecer un plan de acción y medidas internas ${ }^{65}$ para

\footnotetext{
55 Cf. Ibíd., considerando 6.

56 Cf. Ibíd., considerando 4.

57 Cf. Ibíd., considerandos 1, 17.

58 Cf. Ibíd., considerando 3.

59 Cf. Ibíd., considerando 17.

60 Cf. Ibíd., considerando 5.

61 Cf. Ibíd., considerando 9.

62 Cf. Ibíd., considerando 9.

63 Cf. Ibíd., considerando 13.

64 Cf. Ibíd., considerando 14.

65 Cf. Ibíd., considerando 25.
} 
alcanzar tales objetivos, como los sistemas de apoyo a la energía procedente de fuentes renovables ${ }^{66} 67$.

Adicionalmente, se resalta la diferencia entre las garantías de origen ${ }^{68}$ y certificados verdes utilizados para los sistemas de apoyo. Al mismo tiempo, se afirma la dificultad de los Estados para cumplir los objetivos generales indicados en la Directiva para 2020, y con ello, con base en el principio de subsidiariedad previsto en el artículo 5 del Tratado de la Unión ${ }^{69}$, la necesidad de hacer uso de la facultad de adopción de medidas (comunitarias) de la Unión. En este sentido, con base en el principio de proporcionalidad, la Directiva está dentro de lo requerido para el logro de esos objetivos ${ }^{70}$.

En su desarrollo, la Directiva establece en el artículo 1, obligaciones estatales de cumplimiento de "la cuota de energía procedente de fuentes renovables en el consumo final bruto de energía y con la cuota de energía procedente de fuentes renovables en el transporte", así como prevé normas necesarias para su realización y "criterios de sostenibilidad para los biocarburantes y biolíquidos". A continuación, el artículo 2.k define en particular, los sistemas o mecanismos de apoyo para la promoción del uso de energía verde ${ }^{71}$. Esta definición se refiere de forma indeterminada

66 Cf. Ibíd., considerando 19.

67 Los considerandos se refieren a que la gran parte de los Estados miembro adoptan estos sistemas con beneficios dirigidos únicamente a la energía que procede de fuentes renovables establecidas en su territorio y su funcionamiento adecuado depende del grado de control de sus efectos y costos [Cf. Directiva 2009/28/CE, considerando 25]. Además, resaltan la facultad de los Estados miembros de realizar cooperaciones estratégicas transfronterizas [considerando 34] de energía renovable para el cumplimiento de las metas de generación de estas fuentes de energía [considerando 25] con la participación de "las regiones y las autoridades locales" [considerando 34] como sistemas de apoyo conjuntos [considerando 35] y la adopción de otras "medidas de flexibilidad", sin que se afecte la capacidad de alcanzar las metas internas de cada Estado miembro [considerando 36].

68 La Directiva define las garantías de origen como aquellas que "tienen la única función de demostrar al consumidor final que una cuota o cantidad determinada de energía se ha obtenido a partir de fuentes renovables" y son transferibles "de un titular a otro con independencia de la energía a que se refieran" [Directiva 2009/28/CE, considerandos 52, 56].

69 Cf. Unión Europea, Versión consolidada del Tratado de la Unión Europea, C 83/13 Diario Oficial de la Unión Europea, 30 de marzo de 2010. http://www.boe.es/doue/2010/083/Z00013-00046. pdf

70 Cf. Directiva 2009/28/CE, considerando 96.

71 Cf. Ibíd., artículo 2: “[...] k) 'sistema de apoyo': cualquier instrumento, sistema o mecanismo aplicado por un Estado miembro o un grupo de Estados miembros, que promueve el uso de energía procedente de fuentes renovables gracias a la reducción del coste de esta energía, 
al sistema o mecanismo que el Estado miembro o un grupo de Estados miembros apliquen, con el objeto de fomentar el uso de la energía verde, disminuyendo a la vez su costo y aumentando su precio de venta o el volumen de energía renovable adquirida. Lo anterior, por ejemplo, mediante la obligación de utilización de energías renovables o de otra clase de medidas. Como una alternativa para la realización de este objetivo, se prevé el establecimiento de "sistemas de apoyo a la obligación de utilizar energías renovables incluidos los que emplean los 'certificados verdes" [...]. Adicionalmente, el artículo 2.1 define y prevé la posibilidad de establecer la obligación en los sistemas de apoyo a los productores de energía sobre la inclusión en la producción de un porcentaje de energía verde en su oferta (i) o a los consumidores de energía a que utilicen un porcentaje de esta clase de energía (ii) y ello comprende la forma en que tales obligaciones puedan "cumplirse mediante el uso de "certificados verdes".

Concordantemente, el artículo 3.3, literal a) fija la competencia en los Estados miembro de aplicación entre otras medidas, de los sistemas nacionales de apoyo y, en su inciso final, el derecho de estos Estados, conforme a sus artículos 5 a 11, de decidir sobre el nivel de apoyo a la energía que procede de fuentes renovables producida en otro Estado miembro.

\section{2. ¿Aplicación de derecho primario?}

El asunto C-309/02, al que se remite el Tribunal de Justicia en el caso Alands Vindkraft (C-573/12)72, explicó que: "cuando un ámbito ha sido armonizado con carácter exhaustivo en el Derecho comunitario, cualquier medida nacional en este ámbito

aumentando su precio de venta o el volumen de energía renovable adquirida, mediante una obligación de utilizar energías renovables o mediante otras medidas. Ello incluye, sin limitarse a estos, las ayudas a la inversión, las exenciones o desgravaciones fiscales, las devoluciones de impuestos, los sistemas de apoyo a la obligación de utilizar energías renovables incluidos los que emplean los 'certificados verdes', y los sistemas de apoyo directo a los precios, incluidas las tarifas reguladas y las primas".

72 Cf. Unión Europea, Tribunal de Justicia (gran sala), sentencia de 1 de julio de 2014, asunto C-573/12, Ålands Vindkraft AB contra Energimyndigheten, Petición de decisión prejudicial: Förvaltningsrätten i Linköping - Suecia, apartado 57. 
debe apreciarse a la luz de las disposiciones de la medida de armonización y no de las del Derecho primario"73. No obstante, tal como el Tribunal de Justicia constató, la Directiva 2009/28/CE no tiene como finalidad, la armonización de forma exhaustiva de los sistemas de apoyo interno a la electricidad verde $\mathrm{e}^{74} \mathrm{y}$ por ello, la armonización establecida en la Directiva no excluye el examen de la compatibilidad de la normativa sueca objeto de análisis con el artículo 34 TFUE. Todo lo contrario: de conformidad con la Directiva, los Estados miembro son los que definen y tienen la competencia de aplicación de un sistema de apoyo [artículos 3.3, a), 11, 13.3, 4, 22 b), c), anexo VI, 3, c), d), e)]. Por tal razón, las disposiciones objeto de la decisión prejudicial deben evaluarse de conformidad con el derecho primario. En este caso, el examen debe realizarse de forma armónica con las normas del TFUE sobre la libertad de circulación de mercancías.

a. Artículo 34 TFUE

Por consiguiente, debe analizarse si el sistema de apoyo sueco no es compatible con la libertad de circulación de mercancías prevista en el artículo 34 TFUE. Lo anterior se presentaría, en el caso de constituir el mecanismo una restricción cuantitativa a

73 Cf. Unión Europea, Tribunal de Justicia, sentencia de 14 de diciembre de 2004, asunto C-309/02, Radlberger Getränkegesellschaft $m b H \&$ Co., apartado 53. Disponible en: http://curia.europa. $\mathrm{eu} /$ juris/document/document.jsf;jsessionid=9ea7d2dc30d64fe96b007d1f4663adf69128a39 9d768.e34KaxiLc3qMb40Rch0SaxyLbN50?text $=\&$ docid $=49761 \&$ pageIndex $=0 \&$ doclang $=\mathrm{E}$ S\&mode $=1$ st \&dir $=\&$ occ $=$ first $\&$ part $=1 \&$ cid $=921859$

74 Cf. Unión Europea, Tribunal de Justicia (gran sala), sentencia de 1 de julio de 2014, asunto C-573/12, Ålands Vindkraft AB contra Energimyndigheten, Petición de decisión prejudicial: Förvaltningsrätten i Linköping - Suecia, apartados 57 a 63. 


\section{la importación entre los Estados miembros ${ }^{75}$ (i) ${ }^{76}$, o una medida de efecto equivalente a las restricciones cuantitativas ${ }^{77}$ (ii). De forma acorde con los hechos del caso Alands Vindkraft, la} norma sueca establece una obligación a determinados consumidores y proveedores de energía de tener un número de certificados eléctricos conforme a su obligación de cuota calculada sobre la base de la electricidad por ellos consumida o producida ${ }^{78}$.

75 Cf. Unión Europea, Tribunal de Justicia (sala primera), sentencia de 27 de abril de 2017, asunto C-672/15, Noria Distribution SARL, apartado 17. Disponible en: http://curia.europa.eu/juris/ document/document.jsf?text=prohibici $\% 25 \mathrm{C} 3 \% 25 \mathrm{~B} 3 \mathrm{n} \% 2 \mathrm{Bde} \% 2 \mathrm{Brestricciones} \% 2 \mathrm{Bcuantit}$ ativas\&docid $=190163 \&$ pageIndex $=0 \&$ doclang $=E S \&$ mode $=$ req \&dir $=\& o c c=$ first $\&$ part $=1 \& c$ id $=1037895 \#$ ctx 1

76 Por restricciones cuantitativas a la importación de una mercancía comprende el Tribunal de Justicia, tal como resalta la abogado general Trstenjak en el asunto C-205/07, "las medidas que constituyan prohibiciones totales o parciales a la importación, exportación o al tránsito" [Cf. Unión Europea, Tribunal de Justicia, Conclusiones de la abogada general Verica Trstenjak, presentadas el 17 de julio de 2008, Asunto C-205/07, Procedimiento penal contra Lodewijk Gysbrechts y Santurel Inter BVBA [Petición de decisión prejudicial planteada por el Hof van Beroep te Gent (Bélgica)], con remisión al asunto Geddo (2/73, Rec. p. 865), apartado 7. Disponible en: http://eur-lex.europa.eu/legal-content/ES/TXT/HTML/?uri=CELEX:62007C C0205\&from=DE. Unión Europea, Comisión Europea, Dirección C, Política reglamentaria, de la Dirección General de Empresa e Industria, Libre circulación de mercancías, Guía para la aplicación de las disposiciones del Tratado que rigen la libre circulación de mercancías, 12. Adicionalmente, Comunidad Europea, Comisión Europea, Guía para la interpretación y aplicación de los artículos 28 a 30 del Tratado CE, 9 (Bruselas, Comisión Europea, DG de Mercado Interior, enero de 2001). Disponible en: $h$ ttp://www.ppl.nl/passcat.php?sig=EU_GuideArt-28-30_s.pdf]. Estas medidas pueden ser "disposiciones reglamentarias o [...] una práctica administrativa" [Cf. Unión Europea, Comisión Europea, Dirección C, Política reglamentaria, de la Dirección General de Empresa e Industria, Libre circulación de mercancías, Guía para la aplicación de las disposiciones del Tratado que rigen la libre circulación de mercancías, 12]. Ahora bien, de conformidad con el Tribunal de Justicia en el asunto C-148/15, las "medidas de efecto equivalente a las restricciones cuantitativas que establece el artículo 34 TFUE", son "cualquier medida de los Estados miembros que pueda obstaculizar directa o indirectamente, real o potencialmente, las importaciones entre los Estados miembros" [Cf. Unión Europea, Tribunal de Justicia (sala primera), sentencia de 19 de octubre de 2016, asunto C-148/15, Deutsche Parkinson Vereinigung eV y Zentrale zur Bekämpfung unlauteren Wettbewerbs eV, apartado 22. Disponible en: http://curia.europa.eu/juris/document/document.jsf?text=\%2Bre stricciones\%2Bcuantitativas $\% 2 \mathrm{Ba} \% 2 \mathrm{Bla} \% 2 \mathrm{Bimportaci} \% 25 \mathrm{C} 3 \% 25 \mathrm{~B} 3 \mathrm{n} \% 2 \mathrm{Bentre} \% 2 \mathrm{Blos} \% 2$ BEstados\%2Bmiembros\&docid=184671\&pageIndex $=0$ \&doclang $=\mathrm{ES} \&$ mode $=$ req\&dir $=$ \&occ $=$ first\&part=1\&cid=1041198\#ctx1. Comunidades Europeas, Tribunal de Justicia, sentencia de 11 de julio de 1974, asunto 8/74, Procureur du Roi y Benoît y Gustave Dassonville, apartado 5. Disponible en: http://eur-lex.europa.eu/legal-content/ES/TXT/PDF/?uri=CELEX:61974CJ 0008\&from=EN]. Esto es, "el comercio intracomunitario" [Cf. Unión Europea, Tribunal de Justicia (sala quinta), sentencia de 6 de octubre de 2011, asunto C-443/10, Philippe Bonnarde y Agence de Services et de Paiement, apartado 26. Disponible en: http://eur-lex.europa.eu/ legal-content/ES/TXT/HTML/?uri=CELEX:62010CJ0443\&from=ES, con más referencias. Cf. Unión Europea, Tribunal de Justicia (gran sala), sentencia de 1 de julio de 2014, asunto C-573/12, Alands Vindkraft AB contra Energimyndigheten, Petición de decisión prejudicial: Förvaltningsrätten i Linköping - Suecia, apartado 66, con más referencias].

77 Cf. Unión Europea, Tribunal de Justicia (sala primera), sentencia de 27 de abril de 2017, asunto C-672/15, Noria Distribution SARL, apartado 17.

78 Cf. Unión Europea, Tribunal de Justicia (gran sala), sentencia de 1 de julio de 2014, asunto 
Al no haber un convenio internacional sobre la materia entre Suecia y Finlandia, el cumplimiento de esta exigencia se realiza con los certificados verdes del sistema interno sueco y por ello, los importadores proveedores y consumidores de energía, conforme a la normatividad, deben adquirir tales certificados o en caso contrario, abonar el denominado "derecho específico"79. Así, estas medidas tienen la potencialidad de obstaculizar las importaciones de electricidad de otros Estados miembro ${ }^{80}$.

Independientemente de que la norma sueca no establezca una prohibición a los productores de electricidad verde de vender sus certificados eléctricos conjuntamente con la electricidad que producen ${ }^{81}$, esta medida tiene un efecto potencial, como un acto positivo $^{82}$, de impedir el comercio intracomunitario ${ }^{83}$ de importación de energía verde ${ }^{84}$. Por esta razón, tal medida se clasifica como de efecto equivalente a una restricción cuantitativa en el sentido del artículo $34 \mathrm{TFUE}^{85}$.

C-573/12, Ålands Vindkraft AB contra Energimyndigheten, Petición de decisión prejudicial: Förvaltningsrätten i Linköping - Suecia, apartado 68.

79 Cf. Unión Europea, Tribunal de Justicia (gran sala), sentencia de 1 de julio de 2014, asunto C-573/12, Alands Vindkraft AB contra Energimyndigheten, Petición de decisión prejudicial: Förvaltningsrätten i Linköping - Suecia, apartado 69.

80 Cf. Unión Europea, Tribunal de Justicia (gran sala), sentencia de 1 de julio de 2014, asunto C-573/12, Alands Vindkraft AB contra Energimyndigheten, Petición de decisión prejudicial: Förvaltningsrätten i Linköping - Suecia, apartado 70.

81 Cf. Unión Europea, Tribunal de Justicia (gran sala), sentencia de 1 de julio de 2014, asunto C-573/12, Alands Vindkraft AB contra Energimyndigheten, Petición de decisión prejudicial: Förvaltningsrätten i Linköping - Suecia, apartado 71.

82 Cf. Unión Europea, Tribunal de Justicia (gran sala), sentencia de 1 de julio de 2014, asunto C-573/12, Ålands Vindkraft AB contra Energimyndigheten, Petición de decisión prejudicial: Förvaltningsrätten i Linköping - Suecia, apartado 74.

83 Cf. Unión Europea, Tribunal de Justicia (sala quinta), sentencia de 6 de octubre de 2011, asunto C-443/10, Philippe Bonnarde y Agence de Services et de Paiement, apartado 26, con más referencias. Cf. Unión Europea, Tribunal de Justicia (gran sala), sentencia de 1 de julio de 2014, asunto C-573/12, Alands Vindkraft AB contra Energimyndigheten, Petición de decisión prejudicial: Förvaltningsrätten i Linköping - Suecia, apartado 66, con más referencias.

84 Cf. Unión Europea, Tribunal de Justicia (gran sala), sentencia de 1 de julio de 2014, asunto C-573/12, Alands Vindkraft AB contra Energimyndigheten, Petición de decisión prejudicial: Förvaltningsrätten i Linköping - Suecia, apartados 73, 74.

85 Cf. Unión Europea, Tribunal de Justicia (gran sala), sentencia de 1 de julio de 2014, asunto C-573/12, Ålands Vindkraft AB contra Energimyndigheten, Petición de decisión prejudicial: Förvaltningsrätten i Linköping-Suecia, apartado 75. Adicionalmente, Unión Europea, Tribunal de Justicia (sala primera), sentencia de 19 de octubre de 2016, asunto C-148/15, Deutsche Parkinson Vereinigung eV y Zentrale zur Bekämpfung unlauteren Wettbewerbs eV, apartados 22, 27. Unión Europea, Tribunal de Justicia (sala tercera), sentencia de 2 de diciembre de 2004, asunto C-41/02, Comisión de las Comunidades Europeas, contra Reino de los Países Bajos, apartados 38, 40. Disponible en: http://curia.europa.eu/juris/document/document.jsf?text=asunto\%2BC- 


\section{b. Artículo 36 TFUE}

En el asunto C-148/15, el Tribunal de Justicia resaltó cómo, conforme a la jurisprudencia del Tribunal, la aplicación del artículo 36 TFUE constituye una excepción "de interpretación restrictiva" a la regla del artículo 34 TFUE sobre "la libre circulación de mercancías en el interior de la Unión" ".6 La admisión de esta excepción se realiza en un examen de dos niveles. En primer lugar, conforme al asunto C-525/14, la justificación de "una normativa nacional que constituya una medida de efecto equivalente a una restricción cuantitativa a la importación en el sentido del artículo 34 TFUE puede estar justificada por una de las razones de interés general enumeradas en el artículo 36 TFUE o por exigencias imperativas" ${ }^{87}$. En el asunto C-525/14, la jurisprudencia del Tribunal cataloga entre las exigencias imperativas, por ejemplo, las "relativas a la protección del medio ambiente" 88 . En segundo lugar, conforme al asunto C-472/14, la justificación por tales razones está dada, en el evento en que la medida de efecto equivalente sea proporcional ${ }^{89}$. En concreto, la medida es proporcional, cuando "es adecuada para garantizar que se alcance el objetivo perseguido y no va más allá de lo

41\%252F02\&docid $=49727 \&$ pageIndex $=0 \&$ doclang $=E S \&$ mode $=$ req $\&$ dir $=\&$ occ $=$ first\&part $=1$ $\&$ cid=1073636\#ctx1. Unión Europea, Tribunal de Justicia (gran sala), sentencia de 5 de junio de 2007, asunto C-170/04, Klas Rosengren, y otros y Riksåklagaren, apartados 30-36. Disponible en: http://curia.europa.eu/juris/document/document.jsf?text=asunto\%2BC-41\%252F02\&doci $\mathrm{d}=63050$ \& pageIndex $=0 \&$ doclang $=\mathrm{ES} \&$ mode $=$ req $\&$ dir $=\& o c c=$ first\&part $=1 \& \mathrm{cid}=1073636 \mathrm{Ac}$ tx1

86 Cf. Unión Europea, Tribunal de Justicia (sala primera), sentencia de 19 de octubre de 2016, asunto C-148/15, Deutsche Parkinson Vereinigung eV y Zentrale zur Bekämpfung unlauteren Wettbewerbs eV, apartado 29, con más referencias.

87 Cf. Unión Europea, Tribunal de Justicia (sala segunda), sentencia de 22 de septiembre de 2016, asunto C-525/14, Comisión Europea contra República Checa, apoyada por la República Francesa. Disponible en: http://curia.europa.eu/juris/document/document.jsf?text=restricci\% $25 \mathrm{C} 3 \% 25 \mathrm{~B} 3 \mathrm{n} \% 2 \mathrm{Bcuantitativa} \% 2 \mathrm{Ba} \% 2 \mathrm{Bla} \% 2 \mathrm{Bimportaci} \% 25 \mathrm{C} 3 \% 25 \mathrm{~B} 3 \mathrm{n} \&$ docid=183704\&p ageIndex $=0 \&$ doclang $=E S \&$ mode $=$ req $\&$ dir $=\& o c c=$ first $\&$ part $=1 \&$ cid $=72782 \#$ ctx 1

88 Cf. Unión Europea, Tribunal de Justicia (sala segunda), sentencia de 22 de septiembre de 2016, asunto C-525/14, Comisión Europea contra República Checa, apoyada por la República Francesa.

89 Cf. Unión Europea, Tribunal de Justicia (sala segunda), sentencia de 17 de marzo de 2016, asunto C-472/14, Canadian Oil Company Sweden AB, Anders Rantén y Riksåklagaren, apartado 45. Disponible en: http://curia.europa.eu/juris/document/document.jsf?docid $=175163 \&$ mode $=$ req \&pageIndex $=1 \&$ dir $=\&$ occ $=$ first \&part $=1 \&$ text $=\mathrm{C} \% 25 \mathrm{E} 2 \% 2580 \% 2591472 \% 252 \mathrm{~F} 14 \&$ doclang $=\mathrm{ES} \& \mathrm{cid}=69553 \# \mathrm{ct} \mathrm{x} 1$ 
necesario para alcanzarlo" ${ }^{90}$. A ello se refirió el Tribunal en el caso Alands Vindkraft (C-573/12) ${ }^{91}$.

Al analizar cercanamente los considerandos de la Directiva 2009/28/CE se constata que su objeto previsto en el artículo 1 se dirige al fomento de la energía procedente de fuentes renovables para el cumplimiento de meta de la Unión Europea de reducir las emisiones de efecto invernadero y la atención de las correspondientes normas internacionales tales como el Protocolo de Kyoto $^{92}$, así como el crecimiento económico ${ }^{93}$ en la Unión ${ }^{94}$ y su mejoramiento en un " $20 \%$ en la eficiencia energética" a 2020 . Estos postulados hacen parte de las exigencias imperativas de una medida "de efecto equivalente a una restricción cuantitativa a la importación" $" 96$. En particular, en el asunto C-573/12 $2^{97}$, el Tribunal afirmó que la medida de efecto equivalente sueca es acorde con las razones de interés general previstas en el artículo 36 TFUE de "protección de la salud y vida de las personas y animales", y de "preservación de los vegetales"98, así como con

90 Cf. Unión Europea, Tribunal de Justicia (sala segunda), sentencia de 17 de marzo de 2016, asunto C-472/14, Canadian Oil Company Sweden AB, Anders Rantén y Riksåklagaren, apartado 45, con remisión a Unión Europea, Tribunal de Justicia (gran sala), sentencia de 1 de julio de 2014, asunto C-573/12, Alands Vindkraft AB contra Energimyndigheten, Petición de decisión prejudicial: Förvaltningsrätten i Linköping - Suecia, apartado 77.

91 Cf. Unión Europea, Tribunal de Justicia (gran sala), sentencia de 1 de julio de 2014, asunto C-573/12, Ålands Vindkraft AB contra Energimyndigheten, Petición de decisión prejudicial: Förvaltningsrätten i Linköping - Suecia, apartados 76, 77.

92 Cf. Directiva 2009/28/CE, considerando 1.

93 Cf. Directiva 2009/28/CE, considerandos 6, 4.

94 Cf. Directiva 2009/28/CE, considerandos 1, 17.

95 Cf. Directiva 2009/28/CE, considerando 17.

96 Cf. Unión Europea, Tribunal de Justicia (sala segunda), sentencia de 22 de septiembre de 2016, asunto C-525/14, Comisión Europea contra República Checa, apoyada por la República Francesa.

97 Cf. Unión Europea, Tribunal de Justicia (gran sala), sentencia de 1 de julio de 2014, asunto C-573/12, Ålands Vindkraft AB contra Energimyndigheten, Petición de decisión prejudicial: Förvaltningsrätten i Linköping - Suecia, apartados 79-82.

98 Cf. Unión Europea, Tribunal de Justicia (gran sala), sentencia de 1 de julio de 2014, asunto C-573/12, Alands Vindkraft AB contra Energimyndigheten, Petición de decisión prejudicial: Förvaltningsrätten i Linköping - Suecia, apartado 80; con remisión a Unión Europea, Tribunal de Justicia, sentencia de 13 de marzo de 2001, asunto C-379/98, PreussenElektra AG y Schleswag AG, con intervención de Windpark Reußenköge III GmbH y Land Schleswig-Holstein, apartados 73, 75. Esta sentencia resolvió que una "normativa de un Estado miembro que, por una parte, obliga a las empresas privadas suministradoras de electricidad a adquirir la electricidad generada en su zona de suministro por fuentes de energía renovables a precios mínimos superiores al valor económico real de este tipo de electricidad y, por otra, reparte la carga financiera derivada de esta obligación entre dichas empresas suministradoras de electricidad y los gestores privados de redes eléctricas situados en un nivel de distribución anterior no constituye una ayuda de 
el contenido del artículo 194 TFUE, referente al objetivo de la política energética de la Unión de fomento a la eficiencia energética, del ahorro energético y el desarrollo de energías nuevas y renovables ${ }^{99}$, como medidas contra el cambio climático ${ }^{100}$.

El sistema de certificados verdes establecido por la Ley sueca, es una medida de efecto equivalente a una restricción cuantitativa a la importación en el sentido del artículo 34 TFUE, que encuentra asidero en la excepción del artículo 36 TFUE. Esta medida, sin embargo, debe ser proporcional. El objetivo perseguido de la medida sueca es el fomento de la producción de la electricidad verde y no debe ir más allá de lo necesario para su consecución ${ }^{101}$. Al no haber llevado a cabo aún el derecho de la Unión Europea una armonización de los sistemas nacionales de apoyo a la electricidad verde, sería admisible la decisión del Estado miembro correspondiente a que en su territorio, solamente pueda acogerse la forma de apoyo a la producción de electricidad de fuentes renovables que está allí ubicada ${ }^{102}{ }^{103}$. Consecuentemente, Walter Frenz se refiere a la "necesaria relación territorial funcional de un apoyo a la electricidad verde",

Estado". Respecto a ello, Markus Ludwigs, EEG-Umlage und EU-Beihilferecht, Recht der erneuerbaren Energien, REE, 02, 65-76, 70 (2014). Adicionalmente, Carola Glinski, Zu Viel Angst vor dem Europarecht?! Die "Energiewende" Zwischen Nationaler Politikhoheit Und Europäischem Binnenmarkt, 17 Zeitschrift für Europarechtliche Studien, ZEuS, 2, 235-255, 235 (2014). Cf. Nora Grabmayr \& Markus Kahles, Das Recht zur territorial begrenzten Förderung Erneuerbarer Energien, 5 EnergieRecht, ER, 183-187, 185 (2014).

99 Cf. Unión Europea, Tribunal de Justicia (gran sala), sentencia de 1 de julio de 2014, asunto C-573/12, Alands Vindkraft AB contra Energimyndigheten, Petición de decisión prejudicial: Förvaltningsrätten i Linköping - Suecia, apartados 81, 82.

100 Cf. Dörte Fouquet \& Angela Guarrata, Judgment of $1^{\text {st }}$ July 2014 in Allands Vindkraft AB v Energimyndigheten, 5 Renewable Energy Law and Policy, RELP, 1, 52-59, 52 (2014). Disponible en: https://search.proquest.com/docview/1626666684?accountid=13250

101 Cf. Unión Europea, Tribunal de Justicia (sala segunda), sentencia de 17 de marzo de 2016, asunto C-472/14, Canadian Oil Company Sweden AB, Anders Rantén y Riksåklagaren, apartado 45, con remisión a Unión Europea, Tribunal de Justicia (gran sala), sentencia de 1 de julio de 2014, asunto C-573/12, Alands Vindkraft AB contra Energimyndigheten, Petición de decisión prejudicial: Förvaltningsrätten i Linköping - Suecia, apartado 77.

102 Unión Europea, Tribunal de Justicia (gran sala), sentencia de 1 de julio de 2014, asunto C-573/12, Ålands Vindkraft AB contra Energimyndigheten, Petición de decisión prejudicial: Förvaltningsrätten i Linköping - Suecia, apartado 94.

103 Cf. Charlotte Kreuter-Kirchhof, Die Rechtsmaßstäbe des EEG 2014 im Dienst von Klimaschutz, Kostenersparnis und Versorgungssicherheit, 21 Neue Zeitschrift für Verwaltungsrecht, $N V w Z$, 1480-1486, 1486, ítem $I V$, Perspectivas de una generación de energía amigable con el clima (2015). 
como uno de los componentes del esquema de análisis del caso Alands Vindkraft ${ }^{104}$.

Tal como indica el Tribunal de Justicia, es difícil determinar el origen y la fuente de la electricidad, una vez es incorporada en la red en las fases de transmisión, distribución ${ }^{105}$ o consumo ${ }^{106}$. Las garantías de origen en el sentido de la Directiva 2009/28/CE únicamente tienen la función de demostrar al consumidor final que una cantidad de energía se obtuvo de fuentes renovables ${ }^{107}$, sin que por ello tales garantías confieran el derecho a acogerse a determinado sistema de apoyo de un Estado miembro ${ }^{108}$. De lo anterior se diferencian los certificados eléctricos, concedidos por razón de la electricidad de fuentes renovables que se produce en el territorio nacional ${ }^{109}$. Así, el sistema nacional de apoyo a la energía verde se basa en el tipo de energía, en la forma de producción y en el cumplimiento de las metas de reducción de emisiones de efecto invernadero en esa fase ${ }^{110}$. Como indican Nora Grabmayr y Markus Kahles, en este caso, el Tribunal no impuso una obligación de apertura de los sistemas nacionales de apoyo a la producción de energía de fuentes renovables, ni de su interpretación se deriva automáticamente, que el desarrollo del mercado se dirija a una armonización de las reglas de apoyo mediante la denominada integración negativa del mercado ${ }^{111}$.

En concreto, la obligación establecida a los Estados miembros por la Unión mediante la Directiva 2009/28/CE de cuotas de

104 Cf. Walter Frenz, Europarecht, 89 (Springer-Verlag, Berlin, Heidelberg, 2016).

105 Cf. Unión Europea, Tribunal de Justicia (gran sala), sentencia de 1 de julio de 2014, asunto C-573/12, Alands Vindkraft AB contra Energimyndigheten, Petición de decisión prejudicial: Förvaltningsrätten i Linköping - Suecia, apartados $87,88$.

106 Cf. Unión Europea, Tribunal de Justicia (gran sala), sentencia de 1 de julio de 2014, asunto C-573/12, Ålands Vindkraft AB contra Energimyndigheten, Petición de decisión prejudicial: Förvaltningsrätten i Linköping - Suecia, apartado 96.

107 Cf. Directiva 2009/28/CE, considerando 52.

108 Cf. Directiva 2009/28/CE, considerando 56.

109 Cf. Unión Europea, Tribunal de Justicia (gran sala), sentencia de 1 de julio de 2014, asunto C-573/12, Ålands Vindkraft AB contra Energimyndigheten, Petición de decisión prejudicial: Förvaltningsrätten i Linköping - Suecia, apartado 91.

110 Cf. Unión Europea, Tribunal de Justicia (gran sala), sentencia de 1 de julio de 2014, asunto C-573/12, Allands Vindkraft AB contra Energimyndigheten, Petición de decisión prejudicial: Förvaltningsrätten i Linköping - Suecia, apartados 94, 95.

111 Cf. Nora Grabmayr \& Markus Kahles, Das Recht zur territorial begrenzten Förderung Erneuerbarer Energien, 5 EnergieRecht, ER, 183-187, 184, 187 (2014). 
generación de energía verde, brinda a los obligados los instrumentos para su cumplimiento ${ }^{112}$. Primero, está la facultad de los Estados miembros de establecer sistemas nacionales de apoyo y del mismo modo, de realizar cooperaciones con sistemas de apoyo comunes ${ }^{113} 114$. En todo caso, debe indicarse cómo conforme al Tribunal, la limitación territorial del sistema de apoyo sueco no pierde su justificación por el hecho de que su capacidad interna de producción pueda alcanzar las metas asignadas ${ }^{115}$. Por el contrario, al considerar que el costo de producción de la energía verde es más alto que el de la energía producida de fuentes no renovables, el sistema de apoyo tiene como objetivo favorecer las inversiones a largo plazo $^{116}$ en nuevas instalaciones de fuentes de energía renovable y proteger así la confianza legítima de los inversore ${ }^{117}$. El establecimiento de este sistema busca igualmente, que los sobrecostos de la producción de energía verde sean asumidos por el mercado por medio de los proveedores y usuarios de electricidad que tienen la obligación de cuota y "en última instancia", por los consumidores ${ }^{118}$. La imposición de la

112 Cf. Unión Europea, Tribunal de Justicia (gran sala), sentencia de 1 de julio de 2014, asunto C-573/12, Alands Vindkraft AB contra Energimyndigheten, Petición de decisión prejudicial: Förvaltningsrätten i Linköping - Suecia, apartado 98.

113 Cf. Unión Europea, Tribunal de Justicia (gran sala), sentencia de 1 de julio de 2014, asunto C-573/12, Alands Vindkraft AB contra Energimyndigheten, Petición de decisión prejudicial: Förvaltningsrätten i Linköping - Suecia, apartado 100.

114 Este es - por ejemplo - el caso del mecanismo de apoyo integrado entre el Reino de Suecia y el Reino de Noruega. Cf. Unión Europea, Tribunal de Justicia (gran sala), sentencia de 1 de julio de 2014, asunto C-573/12, Ålands Vindkraft AB contra Energimyndigheten, Petición de decisión prejudicial: Förvaltningsrätten i Linköping - Suecia, apartado 101.

115 Cf. Markus Ludwigs, Anmerkung zu EuGH, Urteil v. 01.07.2014, Rs. C-573/12-Ålands Vindkraft AB./.Energimyndigheten, 16 Europäische Zeitschrift für Wirtschaftsrecht, EuZW, 627-628, 628 (2014), quien considera que el nivel alcanzado en la cuota de energía debe estar relacionada con el fomento interno a las plantas de energía de fuentes renovables. El Tribunal debería haber atendido este aspecto y, en caso de considerar dirigirse a ello, la medida no sería proporcional, ni estaría en armonía con el artículo 34 TFUE. Del mismo modo, opina que, si todos los Estados de la Unión consideraran este actuar, la idea de un mercado interno de la energía mediante una parcelación quedaría obsoleta. Por ello, correctamente, indica la necesidad de considerar la apertura del sistema de apoyo a las plantas de energía de fuentes renovables de otros países de la Unión Europea.

116 Cf. Así Walter Frenz, Europarecht, 91 (Springer-Verlag, Berlin, Heidelberg, 2016). Dörte Fouquet \& Angela Guarrata, Judgment of $1^{\text {st }}$ July 2014 in Alands Vindkraft AB contra Energimyndigheten, 5 Renewable Energy Law and Policy, RELP, 1, 52-59, 59 (2014).

117 Cf. Unión Europea, Tribunal de Justicia (gran sala), sentencia de 1 de julio de 2014, asunto C-573/12, Ålands Vindkraft AB contra Energimyndigheten, Petición de decisión prejudicial: Förvaltningsrätten i Linköping - Suecia, apartados 102, 103.

118 Cf. Unión Europea, Tribunal de Justicia (gran sala), sentencia de 1 de julio de 2014, asunto 
obligación de cuota tiene además como finalidad "garantizar a los productores de electricidad verde una demanda de los certificados que se les han concedido", de modo que se facilite un desarrollo de su energía a un precio superior al de la energía de fuentes no renovables ${ }^{119}$, que incite a incrementar la producción de energías renovables ${ }^{120}$.

En este punto, junto con Walter Frenz, debe destacarse cómo la jurisprudencia del Tribunal de Justicia ha considerado también como legitimada la capacidad de funcionamiento de un sistema nacional de apoyo, en los casos de restricciones a la libertad de establecimiento o de prestación de servicios en el sector hospitalario y de cajas sociales, con relación a la limitación territorial de tratamientos médicos ${ }^{121}$, lo que requiere en particular unas condiciones transparentes y objetivas ${ }^{122}$ en el mercado. Precisamente, el Tribunal indica la necesidad de establecer mecanismos, que permitan la realización de un verdadero mercado de certificados verdes y su acceso efectivo en condiciones equitativas que tienda al equilibrio ${ }^{123}$, cuya penalización respecto a la

C-573/12, Ålands Vindkraft AB contra Energimyndigheten, Petición de decisión prejudicial: Förvaltningsrätten i Linköping - Suecia, apartado 111.

119 Cf. Unión Europea, Tribunal de Justicia (gran sala), sentencia de 1 de julio de 2014, asunto C-573/12, Alands Vindkraft AB contra Energimyndigheten, Petición de decisión prejudicial: Förvaltningsrätten i Linköping - Suecia, apartado 111.

120 Cf. Unión Europea, Tribunal de Justicia (gran sala), sentencia de 1 de julio de 2014, asunto C-573/12, Alands Vindkraft AB contra Energimyndigheten, Petición de decisión prejudicial: Förvaltningsrätten i Linköping - Suecia, apartado 112.

121 Así, Walter Frenz, Europarecht, 90 (Springer-Verlag, Berlin, Heidelberg, 2016), con remisión a Unión Europea, Tribunal de Justicia, sentencia de 12 de julio de 2001, asunto C-157/99, B.S.M. Smits, esposa de Geraets, y Stichting Ziekenfonds VGZ y entre H.T.M. Peerbooms y Stichting CZ Groep Zorgverzekeringen, apartado 72. Disponible en: http://curia.europa.eu/juris/document/ document.jsf?text $=\&$ docid $=46529 \&$ pageIndex $=0$ \&doclang $=E S \&$ mode $=1$ st $\&$ dir $=\& o c c=$ first $\&$ part $=1 \&$ cid $=763671$

122 Así Walter Frenz, Europarecht, 90 (Springer-Verlag, Berlin, Heidelberg, 2016), con remisión a Unión Europea, Tribunal de Justicia (gran sala), sentencia de 5 de octubre de 2010, asunto C-512/08, Comisión Europea contra República Francesa, apoyada por: Reino de España, República de Finlandia, Reino Unido de Gran Bretaña e Irlanda del Norte, apartado 43. Disponible en: http://curia.europa.eu/juris/document/document.jsf?text=\&docid=81397\&pageIn $\mathrm{dex}=0 \&$ doclang $=\mathrm{ES} \& \operatorname{mode}=1 \mathrm{st} \& \mathrm{dir}=\& \mathrm{occ}=$ first\&part $=1 \& \mathrm{cid}=780963$ y a Unión Europea, Tribunal de Justicia, sentencia de 13 de mayo de 2003, asunto C-385/99, V.G. Müller-Fauré y Onderlinge Waarborgmaatschappij OZ Zorgverzekeringen UA, y entre E.E.M. van Riet y Onderlinge Waarborgmaatschappij ZAO Zorgverzekeringen, apartado 89. Disponible en: http:// curia.europa.eu/juris/document $/$ document.jsf?text $=\&$ docid $=48278 \&$ pageIndex $=0 \&$ doclang $=$ ES\&mode $=1$ st \&dir $=\&$ occ $=$ first\&part $=1 \&$ cid $=790132$

123 Cf. Unión Europea, Tribunal de Justicia (gran sala), sentencia de 1 de julio de 2014, asunto C-573/12, Alands Vindkraft AB contra Energimyndigheten, Petición de decisión prejudicial: 
obligación de cuota no debe ser excesiva ${ }^{124}$. De conformidad con el Tribunal, la posibilidad de que el derecho sueco permita a los productores de electricidad verde vender a operadores que están sometidos a la obligación de cuota conjuntamente certificados verdes y electricidad, no va más allá del objetivo de incrementar la participación ${ }^{125}$ en la producción de electricidad verde ${ }^{126}$. Por consiguiente, si la norma sueca que establece el sistema de certificados verdes es adecuada para que se alcance el objetivo de fomentar la energía procedente de fuentes renovables, y no va más allá de lo necesario para su realización, entonces, la medida examinada es proporcional $1^{127} 128$.

Förvaltningsrätten i Linköping - Suecia, apartado 116.

124 Cf. Unión Europea, Tribunal de Justicia (gran sala), sentencia de 1 de julio de 2014, asunto C-573/12, Alands Vindkraft AB contra Energimyndigheten, Petición de decisión prejudicial: Förvaltningsrätten i Linköping - Suecia, apartado 116.

125 Clemens Latzel, Soziale Aspekte bei der Vergabe öffentlicher Aufträge nach der Richtlinie 2014/24/EU, 11 Neue Zeitschrift für Bau, NZBau, 673-681, 674 (2014). Disponible en: http:// www.jura.uni-muenchen.de/personen/1/latzel/schriftenverzeichnis/c12014-1.pdf

126 Cf. Unión Europea, Tribunal de Justicia (gran sala), sentencia de 1 de julio de 2014, asunto C-573/12, Alands Vindkraft AB contra Energimyndigheten, Petición de decisión prejudicial: Förvaltningsrätten i Linköping - Suecia, apartado 116; adicionalmente, Clemens Latzel, Soziale Aspekte bei der Vergabe öffentlicher Aufträge nach der Richtlinie 2014/24/EU, 11 Neue Zeitschrift für Bau, NZBau, 673-681, 674 (2014).

127 Cf. Unión Europea, Tribunal de Justicia (sala segunda), sentencia de 17 de marzo de 2016, asunto C-472/14, Canadian Oil Company Sweden AB, Anders Rantén y Riksåklagaren, apartado 45. Unión Europea, Tribunal de Justicia (gran sala), sentencia de 1 de julio de 2014, asunto C-573/12, Alands Vindkraft AB contra Energimyndigheten, Petición de decisión prejudicial: Förvaltningsrätten i Linköping - Suecia, apartado 119. Cf. Adicionalmente, cf. Geert van Calster, Climate Change and Renewable Energy as a Super Trump for EU Trade Law: However All Essent Clear, 5 Renewable Energy Law and Policy, RELP, 1, 60-66, 65 (2014). Disponible en: https://search.proquest.com/docview/1626666771?accountid=13250, quien opina que la interpretación dada por el Tribunal de Justicia fue orientada de forma cercana a la operación del sistema de apoyo en el mercado.

128 Finalmente, el Tribunal de Justicia definió como competencia del Tribunal de lo Contencioso Administrativo de Linköping el examen con base en la hermenéutica del tenor, la finalidad o la sistemática de la normatividad sueca y la garantía del principio de seguridad jurídica, el cual exige que los interesados conozcan con exactitud el alcance de las obligaciones impuestas y sus derechos y obligaciones, de modo que pueda adoptar las medidas que considere adecuadas [Cf. Unión Europea, Tribunal de Justicia (gran sala), sentencia de 1 de julio de 2014, asunto C-573/12, Alands Vindkraft AB contra Energimyndigheten, Petición de decisión prejudicial: Förvaltningsrätten i Linköping - Suecia, apartados 126-129]. En todo caso, el Tribunal de Justicia no considera que la norma analizada pueda vulnerar el principio de seguridad jurídica [Cf. Unión Europea, Tribunal de Justicia (gran sala), sentencia de 1 de julio de 2014, asunto C-573/12, Alands Vindkraft AB contra Energimyndigheten, Petición de decisión prejudicial: Förvaltningsrätten i Linköping - Suecia, apartado 131]. 


\section{VigenCia Del ARTículo 3.3 Directiva 2009/28/CE}

El abogado general Bot propuso al Tribunal, con base en el contenido del artículo $267 \mathrm{TFUE}^{129}$, la declaratoria de invalidez del artículo 3.3 de la Directiva 2009/28/CE, por incompatibilidad con el contenido del artículo $34 \mathrm{TFUE}^{130}$. El artículo 3.3 de la Directiva 2009/28/CE establece la competencia en cada Estado miembro de adoptar medidas como los sistemas de apoyo o mecanismos de cooperación entre los Estados miembros e incluso con terceros países. Lo anterior, con la finalidad de que cada Estado miembro esté en la posibilidad de cumplir los objetivos nacionales obligatorios de la cuota de energía procedente de fuentes renovables, conforme a los incisos 1 y 2 del artículo 3 de la Directiva 2008/28 CE. Adicionalmente, esta norma concede la potestad a los Estados obligados de establecer, conforme a la Directiva (artículos 5-11), el nivel de apoyo a la energía producida de fuentes renovables en otro Estado miembro.

Al analizar las cuestiones prejudiciales planteadas por el Tribunal de lo Contencioso Administrativo de Linköping, no se encuentra que su objeto era el examen de validez de la Directiva 2009/28/CE ${ }^{131}$. Por el contrario, la remisión de Linköping al Tribunal de Justicia se realizó en virtud de la "relación de cooperación"132 de conocer previamente la interpretación de las disposiciones de este acto comunitario ${ }^{133}$ en el ámbito del

129 Cf. Unión Europea, Tribunal de Justicia, asunto C-573/12, Ålands Vindkraft AB contra Energimyndigheten, Conclusiones del Abogado General Yves Bot, presentadas el 28 de enero de 2014, apartado 67, con remisión a Comunidades Europeas, Tribunal de Justicia, sentencia de 1 de diciembre de 1965, asunto 16/65, C. Schwarze contra Einfuhr- und Vorratsstelle für Getreide und Futtermittel (Schwarze), 269.

130 Cf. Unión Europea, Tribunal de Justicia, asunto C-573/12, Ålands Vindkraft AB contra Energimyndigheten, Conclusiones del Abogado General Yves Bot, presentadas el 28 de enero de 2014, apartado 72. Respecto al alcance de esta competencia invocada, Bärbel Sachs, Die Ex-officio-Prüfung durch die Gemeinschaftsgerichte, 80 (Mohr Paul Siebeck, Tübingen, 2008).

131 Otra opinión, Unión Europea, Tribunal de Justicia, asunto C-573/12, Alands Vindkraft AB contra Energimyndigheten, Conclusiones del Abogado General Yves Bot, presentadas el 28 de enero de 2014, apartado 67.

132 Cf. Christian Koenig \& Andreas Haratsch, Europarecht, 152 (4ª ed., J. C. B. Mohr Paul Siebeck, Tübingen, 2003).

133 Cf. Comunidades Europeas, Tribunal de Justicia, sentencia de 1 de diciembre de 1965, asunto 16/65, C. Schwarze contra Einfuhr-und Vorratsstelle für Getreide und Futtermittel (Schwarze), 269. 
artículo 267.2 TFUE. De conformidad con el artículo 3.3 TUE, debe destacarse que el establecimiento del mercado interior de la Unión Europea se dirige al desarrollo sostenible en fomento de un alto nivel de protección y mejora de la calidad del medio ambiente.

A continuación, la constelación normativa conformada por los artículos 11, 4.2.e y 191-193 del TFUE indica cómo la protección ambiental y la lucha contra el cambio climático deben acuñar las políticas y acciones de la Unión Europea para la protección de las personas y su entorno. Este mandato es reafirmado por el artículo 37 de la Carta de los Derechos Fundamentales de la Unión Europea al exigir como un derecho de solidaridad, la protección ambiental mediante su concreción en las políticas de integración de la Unión y su garantía conforme al "principio de desarrollo sostenible". Acorde con Ludwigs, la sistemática de los artículos 192 II c, 291 I y principalmente $194^{134}$ del TFUE resalta la competencia de los Estados miembros de elegir las fuentes energéticas y establecer la estructura general del abastecimiento energético $^{135}$. Esta competencia es armónica con el contenido del artículo 3.3 de la Directiva 2009/28/CE.

Posteriormente, en el asunto C-492/14 ${ }^{136}$, el Tribunal de Justicia reiteró la posibilidad de justificación de la limitación del comercio interior de la Unión Europea por exigencias imperativas de protección ambiental, y en especial, por el fomento a "la utilización de las fuentes de energía renovables para la producción de electricidad", con el objeto de proteger "la salud

134 En este fundamento normativo también encuentra asidero la Unión Europea, Comisión Europea, Informe de la Comisión al Parlamento Europeo, al Consejo, al Comité Económico y Social Europeo y al Comité de las Regiones. Informe de situación en materia de energías renovables, COM (2017) 57 final, 1 de febrero de 2017. Disponible en: http://eur-lex.europa.eu/legal-content/ ES/TXT/?uri=CELEX\%3A52017DC0057

135 Cf. Markus Ludwigs, Grenzen für eine nationale Energiepolitik im EU-Binnenmarkt, 11 Zeitschrift für das gesamte Energiewirtschaftsrecht, EnWZ, 483-488, 487 (2013).

136 Cf. Unión Europea, Tribunal de Justicia (sala segunda), sentencia de 29 de septiembre de 2016, asunto C-492/14, Essent Belgium NV y Vlaams Gewest, Inter-Energa, IVEG, Infrax West, Provinciale Brabantse Energiemaatschappij CVBA (PBE), Vlaamse Regulator van de Elektriciteits- en Gasmarkt (VREG). Disponible en: http://curia.europa.eu/juris/document/ document.jsf;jsessionid=9ea7d0f130d5c4af334e98084a91bd7dfcd9992e1102.e34KaxiLc3eQ c40LaxqMbN4PaxiLe0?text $=\&$ docid $=183925 \&$ pageIndex $=0 \&$ doclang $=$ ES\&mode $=1$ st $\&$ dir $=\&$ occ $=$ first $\&$ part $=1 \&$ cid $=197617$ 
y la vida de las personas y animales y la preservación de los vegetales", como "razones de interés general"137. Del mismo modo, en el ámbito de los certificados verdes como un sistema de apoyo que tiene como epicentro a los productores de energía verde, el Tribunal se refirió a su efecto incitativo en el incremento de la producción de la electricidad verde, a pesar de los costos que incorpora ${ }^{138}$, y en la potencialidad de que tales permitan alcanzar el objetivo ambiental previsto ${ }^{139}$, así como a la promoción de las inversiones a largo plazo en nuevas instalaciones y la concesión de garantías a los productores para la "comercialización futura de su producción de electricidad verde" 140 .

En especial debe considerarse que la Directiva 2009/28/CE, como detalla Carola Glinski, brinda a los Estados miembros de la Unión márgenes de acción ${ }^{141}$ para el fomento de energías renovables que encuentran fundamento más que desde la libertad de circulación de mercancías, en el derecho europeo de ayudas estatales $^{142}$. En el evento de considerar - junto con la Comi-

137 Cf. Unión Europea, Tribunal de Justicia (sala segunda), sentencia de 29 de septiembre de 2016, asunto C-492/14, Essent Belgium NV y Vlaams Gewest, Inter-Energa, IVEG, Infrax West, Provinciale Brabantse Energiemaatschappij CVBA (PBE), Vlaamse Regulator van de Elektriciteits- en Gasmarkt (VREG), apartado 101.

138 Cf. Unión Europea, Tribunal de Justicia (sala segunda), sentencia de 29 de septiembre de 2016, asunto C-492/14, Essent Belgium NV y Vlaams Gewest, Inter-Energa, IVEG, Infrax West, Provinciale Brabantse Energiemaatschappij CVBA (PBE), Vlaamse Regulator van de Elektriciteits- en Gasmarkt (VREG), apartado 115.

139 Cf. Unión Europea, Tribunal de Justicia (sala segunda), sentencia de 29 de septiembre de 2016, asunto C-492/14, Essent Belgium NV y Vlaams Gewest, Inter-Energa, IVEG, Infrax West, Provinciale Brabantse Energiemaatschappij CVBA (PBE), Vlaamse Regulator van de Elektriciteits- en Gasmarkt (VREG), apartado 109, con más referencias.

140 Cf. Unión Europea, Tribunal de Justicia (sala segunda), sentencia de 29 de septiembre de 2016, asunto C-492/14, Essent Belgium NV y Vlaams Gewest, Inter-Energa, IVEG, Infrax West, Provinciale Brabantse Energiemaatschappij CVBA (PBE), Vlaamse Regulator van de Elektriciteits- en Gasmarkt (VREG), apartado 110, con más referencias.

141 Cf. Nora Grabmayr \& Markus Kahles, Das Recht zur territorial begrenzten Förderung Erneuerbarer Energien, 5 EnergieRecht, ER, 183-187, 186 (2014).

142 Así, Carola Glinski, Kein Zwang zur Öffnung nationaler Fördersysteme für erneuerbare Energien zugunsten ausländischer Hersteller. Anmerkung zu EuGH, Urteil vom 1.7.2014, Rs. C-573/12 Allands Vindkraft AB gegen Energimyndigheten, 5 Europarecht, EuR, 567-575, 574, 575 (2014), con remisión a Unión Europea, Comunicación de la Comisión de la Unión Europea, Directrices sobre ayudas estatales en materia de protección del medio ambiente y energía 2014-2020, (2014/C 200/01), C 200/01 Diario Oficial de la Unión Europea, 28 de junio de 2014. Disponible en: http://eur-lex.europa.eu/legal-content/ES/TXT/HTML/?uri=CELEX:52014XC 0628(01)\&from=DE 
sión - este fomento como una ayuda estatal ${ }^{143}{ }^{144}$, pudiera —en el sentido de Frenz- estar eventualmente justificado el trato desigual frente a las plantas de energía renovable ubicadas en el territorio de otros Estados miembro, en la compatibilidad con el mercado interior europeo de las ayudas previstas en el artículo 107.3, b) ${ }^{145} \mathrm{TFUE}^{146}$ y en este sentido, en la "protección del clima en la forma de una economía de baja emisión de $\mathrm{CO} 2$ "147.

\section{LA PROPUESTA DE LA COMISIÓN EUROPEA 2020- 2030 Y DE MEDIDAS DE ENERGÍA LIMPIA EN EUROPA}

En el asunto C-573/12, el Tribunal de Justicia consideró la armonía con el derecho europeo del sistema sueco de apoyo a la producción de energía verde en su territorio ${ }^{148}{ }^{149}$. En todo caso, la Comisión ha resaltado la necesidad de que el apoyo a energías renovables también se amplíe a la energía de plantas generadoras ubicadas en otros Estados miembro ${ }^{150}$. Desde la perspectiva de Glinski, en el ámbito del derecho de ayudas estatales, es necesario "un ajuste del sistema de modelo de mercado interno que tendría finalmente como meta una europeización de este"'151, y el que la integración de tales sistemas de apoyo

143 Cf. Armin Steinbach, Renewable Energy and the Free Movement of Goods, 1-20, 19 (Nuffield College Working Paper Series in Politics, Robert Brückmann Head, Policy Department, Eclareon, 2015), quien opina que un mercado sin barreras de la electricidad en la Unión Europea aún no es una realidad.

144 Walter Frenz, Europarecht, 90 (Springer-Verlag, Berlin, Heidelberg, 2016).

145 Como las "[...] destinadas a reparar los perjuicios causados por desastres naturales o por otros acontecimientos de carácter excepcional". Artículo 107.3, b) TFUE.

146 Walter Frenz, Europarecht, 90 (Springer-Verlag, Berlin, Heidelberg, 2016).

147 Walter Frenz, Europarecht, 90 (Springer-Verlag, Berlin, Heidelberg, 2016).

148 Cf. Unión Europea, Tribunal de Justicia (gran sala), sentencia de 1 de julio de 2014, asunto C-573/12, Allands Vindkraft AB contra Energimyndigheten, Petición de decisión prejudicial: Förvaltningsrätten i Linköping - Suecia. Disponible en: http://curia.europa.eu/juris/liste. jsf?language $=$ es\&num $=\mathrm{C}-573 / 12$

149 Cf. Christian Kahle, Die beihilfenrechtliche Genehmigung des EEG 2014 durch die Europäische Kommission Eine kritische Würdigung, 23 Neue Zeitschrift für Verwaltungsrecht, $N V w Z$, 1563-1566, 1566 (2014).

150 Cf. Christian Kahle, Die beihilfenrechtliche Genehmigung des EEG 2014 durch die Europäische Kommission Eine kritische Würdigung, 23 Neue Zeitschrift für Verwaltungsrecht, $N V w Z$, 1563-1566, 1566 (2014).

151 Carola Glinski, Kein Zwang zur Öffnung nationaler Fördersysteme für erneuerbare Energien zugunsten ausländischer Hersteller. Anmerkung zu EuGH, Urteil vom 1.7.2014, Rs. C-573/12 Alands Vindkraft AB gegen Energimyndigheten, 5 Europarecht, EuR, 567-575, 574-575 (2014), 
resultara por medio de un proceso político ${ }^{152}{ }^{153}$. Esto es, en el ámbito de acción de los Estados miembro y del legislador de la Unión Europea ${ }^{154}$, para el alcance de las metas de protección contra el cambio climático, como las descritas por la Comisión Europea en la comunicación del "marco estratégico en materia de clima y energía para el período 2020-2030"155.

Esta armonización legislativa tiene como epicentro la Directiva 2009/28/CE sobre energías renovables ${ }^{156}$, conforme lo resaltó el informe de la Comisión de situación en materia de energías renovables de 2017 y desde su perspectiva, el paquete de medidas propuesto y denominado "energía limpia para todos los europeos"157 debe concretarse. Del mismo modo, la Comisión indicó la necesidad de modernizar la economía de la Unión Europea, mediante el aceleramiento de la transición hacia una energía limpia, así como del crecimiento y la creación de empleo ${ }^{158}$. Finalmente, la Comisión presentó en su programa

con remisión a la Unión Europea, Comunicación de la Comisión de la Unión Europea, Directrices sobre ayudas estatales en materia de protección del medio ambiente y energía 2014-2020, (2014/C 200/01), C 200/01 Diario Oficial de la Unión Europea, 28 de junio de 2014.

152 Cf. Carola Glinski, Zu Viel Angst vor dem Europarecht?! Die "Energiewende" Zwischen Nationaler Politikhoheit Und Europäischem Binnenmarkt, 17 Zeitschrift für Europarechtliche Studien, ZEuS, 2, 235-255, 250 (2014).

153 Con todo, con base en el asunto C-573/12, Nora Grabmayr y Markus Kahles señalan que "la armonización a nivel europeo debe resultar a través de la legislación y no puede ser forzada a través del rodeo de la libre circulación de mercancías". Cf. Nora Grabmayr \& Markus Kahles, Das Recht zur territorial begrenzten Förderung Erneuerbarer Energien, 5 EnergieRecht, ER, 183-187, 187 (2014).

154 Nora Grabmayr \& Markus Kahles, Das Recht zur territorial begrenzten Förderung Erneuerbarer Energien, 5 EnergieRecht, ER, 183-187, 186 (2014).

155 Cf. Unión Europea, Comisión Europea, Comunicación de la Comisión al Parlamento Europeo, al Consejo, al Comité Económico y Social Europeo y al Comité de las Regiones. Un marco estratégico en materia de clima y energía para el período 2020-2030, COM/2014/015 final, 22 de enero de 2014. Disponible en: http://eur-lex.europa.eu/legal-content/ES/TXT/HTML/?uri $=$ CELEX:52014DC0015\& from $=\mathrm{DE}$

156 Cf. Unión Europea, Comisión Europea, Informe de la Comisión al Parlamento Europeo, al Consejo, al Comité Económico y Social Europeo y al Comité de las Regiones. Informe de situación en materia de energías renovables, COM (2017) 57 final, 1 de febrero de 2017.

157 Cf. Unión Europea, Comisión Europea, Comunicación de la Comisión al Parlamento Europeo, al Consejo, al Comité Económico y Social Europeo, al Comité de las Regiones y al Banco Europeo de Inversiones. Energía limpia para todos los europeos, Bruselas, 30 de noviembre de 2016 COM (2016) 860 final. Disponible en: http://eur-lex.europa.eu/legal-content/ES/TXT/ HTML/?uri=CELEX:52016DC0860(01)\&from=ES

158 Cf. Unión Europea, Comisión Europea, Comunicación de la Comisión al Parlamento Europeo, al Consejo, al Comité Económico y Social Europeo, al Comité de las Regiones y al Banco Europeo de Inversiones. Energía limpia para todos los europeos, Bruselas, 30 de noviembre de 2016 COM (2016) 860 final, 2. 
de trabajo para 2017, propuestas reglamentarias y de medidas en este ámbito, en el cual tiene presente la implementación ${ }^{159}$ del Acuerdo de París ratificado en $2016^{160}$ y el umbral del $27 \%$ de la cuota vinculante de energías renovables consumida por la Unión Europea en $2030^{161}{ }^{162}$. Además considera un correlativo compromiso político de gobernanza ${ }^{163}$ de los Estados miembro de desarrollar este objetivo colectivo en sus planes de energía y clima $^{164}$, con la correspondiente eliminación de las barreras de crecimiento de las energías renovables ${ }^{165}$.

159 Cf. Unión Europea, Comisión Europea, Comunicación de la Comisión al Parlamento Europeo, al Consejo, al Comité Económico y Social Europeo, al Comité de las Regiones y al Banco Europeo de Inversiones. Energía limpia para todos los europeos, Bruselas, 30 de noviembre de 2016 COM (2016) 860 final.

160 Cf. Unión Europea, Comisión Europea, Comunicación de la Comisión al Parlamento Europeo, al Consejo, al Comité Económico y Social Europeo, al Comité de las Regiones y al Banco Europeo de Inversiones. Energía limpia para todos los europeos, Bruselas, 30 de noviembre de 2016 COM (2016) 860 final.

161 Cf. Unión Europea, Comisión Europea, Comunicación de la Comisión al Parlamento Europeo, al Consejo, al Comité Económico y Social Europeo y al Comité de las Regiones. Un marco estratégico en materia de clima y energía para el período 2020-2030, COM/2014/015 final, 22 de enero de 2014, numeral 2.

162 Cf. Unión Europea, Comisión Europea, Comunicación de la Comisión al Parlamento Europeo, al Consejo, al Comité Económico y Social Europeo, al Comité de las Regiones y al Banco Europeo de Inversiones. Energía limpia para todos los europeos, Bruselas, 30 de noviembre de 2016 COM (2016) 860 final.

163 Cf. James Kröger, Das EEG 2014 im Lichte der Europäisierung des Rechts der Erneuerbaren Energien, 38 Natur und Recht, NuR, 2, 85-90, 86 (2016).

164 Cf. Unión Europea, Comisión Europea, Comunicación de la Comisión al Parlamento Europeo, al Consejo, al Comité Económico y Social Europeo, al Comité de las Regiones y al Banco Europeo de Inversiones. Energía limpia para todos los europeos, Bruselas, 30 de noviembre de 2016 COM (2016) 860 final, 8.

165 Cf. Unión Europea, Comisión Europea, Informe de la Comisión al Parlamento Europeo, al Consejo, al Comité Económico y Social Europeo y al Comité de las Regiones. Informe de situación en materia de energías renovables, COM (2017) 57 final, 1 de febrero de 2017. 


\section{Conclusiones}

- La protección ambiental y el desarrollo sostenible constituyen una parte de la cimentación profunda de la estructura del derecho europeo. Ello puede verificarse en el contenido del artículo 3.3 TUE y de los artículos 11, 4.2.e, y 191 a 194 TFUE, así como del artículo 37 de la Carta de los Derechos Fundamentales de la Unión Europea. Del mismo modo, los artículos 11, 4.2.e, y 191 a 193 del TFUE establecen a la protección ambiental y contra el cambio climático como un componente medular de las políticas y acciones de la Unión Europea. En particular, el artículo 3.3 de la Directiva 2009/28/CE es válido como derecho secundario y armónico con el contenido de los artículos 34 y 36 del TFUE, en lo referente a la competencia asignada a los Estados miembros para la adopción de medidas dirigidas al uso de energía procedente de fuentes renovables y a la consecución de las obligaciones de la cuota europea de energía verde. Ello es concordante con la competencia de los Estados miembros resaltada por Ludwigs en los artículos 192 II c, 291 I y 194 $4^{166}$, para elegir las fuentes energéticas y la estructura del abastecimiento energético ${ }^{167}$.

- En consecuencia, la decisión prejudicial en el asunto Ålands Vindkraft (C-573/12) por parte del Tribunal de Justicia estableció que el sistema de apoyo analizado constituye una medida de efecto equivalente a una restricción cuantitativa en el sentido del artículo 34 TFUE $^{168}$. Esta medida es autorizada por el artículo 36 TFUE, por razones de interés general de

166 Cf. Adicionalmente, Unión Europea, Comisión Europea, Informe de la Comisión al Parlamento Europeo, al Consejo, al Comité Económico y Social Europeo y al Comité de las Regiones. Informe de situación en materia de energías renovables, COM (2017) 57 final, 1 de febrero de 2017.

167 Cf. Markus Ludwigs, Grenzen für eine nationale Energiepolitik im EU-Binnenmarkt, 11 Zeitschrift für das gesamte Energiewirtschaftsrecht, EnWZ, 483-488, 487 (2013).

168 Cf. Unión Europea, Tribunal de Justicia (gran sala), sentencia de 1 de julio de 2014, asunto C-573/12, Alands Vindkraft AB contra Energimyndigheten, Petición de decisión prejudicial: Förvaltningsrätten i Linköping - Suecia, apartado 80. 
protección ambiental ${ }^{169}$, es proporcional ${ }^{170}$ y armónica con el fomento de las energías renovables ${ }^{171}$ (194.1 TFUE), así como con la reducción de las emisiones de efecto invernadero ${ }^{172} \mathrm{y}$ con la protección contra el cambio climático ${ }^{173}$.

- Los esfuerzos de la Comisión pueden a su vez encontrar un cercano equilibrio en la modernización de la economía y el fortalecimiento de las energías renovables, con la necesaria participación conjunta del Parlamento y el Consejo Europeo $^{174}$. Del mismo modo, la estabilidad y el avance de la estructura del derecho europeo hacen viable dar un paso más allá en el proceso de armonización del derecho en Europa para el fomento de las energías renovables y el crecimiento económico con protección del medio ambiente y desarrollo sostenible. Estas acciones encuentran especial armonía con los contenidos del Acuerdo de París de cambio climático, que promueve la integridad de todos los ecosistemas así como

169 Cf. Unión Europea, Tribunal de Justicia (gran sala), sentencia de 1 de julio de 2014, asunto C-573/12, Alands Vindkraft AB contra Energimyndigheten, Petición de decisión prejudicial: Förvaltningsrätten i Linköping - Suecia, apartado 80. Carola Glinski, Zu Viel Angst vor dem Europarecht?! Die “Energiewende” Zwischen Nationaler Politikhoheit Und Europäischem Binnenmarkt, 17 Zeitschrift für Europarechtliche Studien, ZEuS, 2, 235-255, 235 (2014). Nora Grabmayr \& Markus Kahles, Das Recht zur territorial begrenzten Förderung Erneuerbarer Energien, 5 EnergieRecht, ER, 183-187, 185 (2014).

170 Finalmente, el Tribunal de Justicia definió como competencia del Tribunal de lo Contencioso Administrativo de Linköping el examen con base en la hermenéutica del tenor, la finalidad o la sistemática de la normatividad sueca y la garantía del principio de seguridad jurídica, el cual exige que los interesados conozcan con exactitud el alcance de las obligaciones impuestas y sus derechos y obligaciones, de modo que pueda adoptar las medidas que considere adecuadas [Cf. Unión Europea, Tribunal de Justicia (gran sala), sentencia de 1 de julio de 2014, asunto C-573/12, Allands Vindkraft AB contra Energimyndigheten, Petición de decisión prejudicial: Förvaltningsrätten i Linköping - Suecia, apartados 126-129]. En todo caso, el Tribunal de Justicia no considera que la norma analizada pueda vulnerar el principio de seguridad jurídica [Cf. Unión Europea, Tribunal de Justicia (gran sala), sentencia de 1 de julio de 2014, asunto C-573/12, Alands Vindkraft AB contra Energimyndigheten, Petición de decisión prejudicial: Förvaltningsrätten i Linköping - Suecia, apartado 131].

171 Cf. Unión Europea, Tribunal de Justicia (gran sala), sentencia de 1 de julio de 2014, asunto C-573/12, Ålands Vindkraft AB contra Energimyndigheten, Petición de decisión prejudicial: Förvaltningsrätten i Linköping - Suecia, apartados $81,82$.

172 Cf. Considerando 1, Directiva 2009/28/CE.

173 Cf. Dörte Fouquet \& Angela Guarrata, Judgment of $1^{\text {st }}$ July 2014 in Alands Vindkraft AB contra Energimyndigheten, 5 Renewable Energy Law and Policy, RELP, 1, 52-59, 52 (2014).

174 Cf. Unión Europea, Comisión Europea, Informe de la Comisión al Parlamento Europeo, al Consejo, al Comité Económico y Social Europeo y al Comité de las Regiones. Informe de situación en materia de energías renovables, COM (2017) 57 final, 1 de febrero de 2017. 
un esfuerzo mundial por la movilización de la financiación para la protección del clima (artículo 9.3) ${ }^{175}$.

- La aplicación de las formas de apoyo a la producción de energías renovables y la finalidad de la propuesta reguladora de la Comisión son concordantes con los objetivos del Acuerdo de París y la protección contra el cambio climático. Estos esfuerzos viabilizan la adopción europea de un sistema energético limpio, por medio entre otros, de mecanismos de mercado con la consecuente disminución de gases de efecto invernadero y la maximización del crecimiento económico, así como de la inversión en nuevas tecnologías, el fomento empresarial y el empleo en el ámbito del desarrollo sostenible $^{176}$.

175 Cf. Organización de las Naciones Unidas, ONU, Convención de Naciones Unidas sobre cambio climático, París, 12 de diciembre de 2015. Disponible en: https://unfecc.int/files/meetings/ paris_nov_2015/application/pdf/paris_agreement_spanish_.pdf. Unión Europea, Declaración de la Unión Europea de conformidad con el artículo 20, párrafo 3, del Acuerdo de París, L 282/4 Diario Oficial de la Unión Europea, 19 de octubre de 2016. Disponible en: http://eur-lex. europa.eu/legal-content/ES/TXT/?uri=CELEX:22016A1019(01)

176 Cf. Comunicación de la Comisión al Parlamento Europeo, al Consejo, al Comité Económico y Social Europeo, al Comité de las Regiones y al Banco Europeo de Inversiones. Energía limpia para todos los europeos, Bruselas, 30.11.2016 COM (2016) 860 final. Adicionalmente, Unión Europea, Comisión Europea, Anexo. Medidas para impulsar la transición hacia una energía limpia de la Comunicación de la Comisión al Parlamento Europeo, al Consejo, al Comité Económico y Social Europeo, al Comité de las Regiones y al Banco Europeo de Inversiones Energía limpia para todos los europeos, en especial nota 13. Disponible en: http://eur-lex.europa. eu/legal-content/ES/TXT/HTML/?uri=CELEX:52016DC0860(01)\&from=ES 


\section{BIBLIOGRAFÍA}

\section{Libros}

Aguilera-Nieves, Antonio, Gestión del mantenimiento de instalaciones de energía eólica (Editorial Vértice, Málaga, 2012).

Arndt, Hans-Wolfgang; Fischer, Kristian \& Fetzer, Thomas, Europarecht (C.F. Müller, Heidelberg, 2015).

Baena, Antonio \& Pueyo, Ana, Competitividad y cambio climático: nuevos retos para la industria española (Colección EOI Medio Ambiente, EOI Escuela de Organización Industrial, España, 2007). Disponible en: https://www.eoi.es/es/ savia/publicaciones/20596/competitividad-y-cambio-climatico-nuevos-retos-parala-industria-espanola

Fastenrath, Ulrich \& Groh, Thomas, Europarecht (3 $3^{\text {a }}$ ed., Boorberg, Stuttgart, 2012).

Frenz, Walter, Europarecht (Springer-Verlag, Berlin, Heidelberg, 2016).

Frenz, Walter, Handbuch Europarecht, Band 1, Europäische Grundfreiheiten (2a ed., Springer, Heidelberg, 2012).

Hailbronner, Kay \& Jochum, Georg, Europarecht II, Binnenmarkt und Grundfreiheiten (Verlag W. Kohlhammer GmbH, Stuttgart, 2006).

Herdegen, Matthias, Principles of International Economic Law (Oxford University, Oxford, 2016).

Koenig, Christian \& Haratsch, Andreas, Europarecht (4 ${ }^{\text {a }}$ ed., J. C. B. Mohr Paul Siebeck, Tübingen, 2003).

Lippert, André, Der grenzüberschreitende Sachverhalt im Unionsrecht: Eine Analyse anhand der Rechtsprechung des Europäischen Gerichtshofs zu den Kontrollkompetenzen (Mohr Siebeck, Tübingen, 2013).

Muriel-Ciceri, José Hernán, Die Übertragung der Abfallentsorgung auf Dritte (Hartung-Gorre Verlag, Konstanz, 2006).

Pelte, Dietrich, Die Zukunft unserer Energieversorgung. Eine Analyse aus mathematisch-naturwissenschaftlicher Sicht (Springer-Verlag, Wiesbaden, 2014).

Sachs, Bärbel, Die Ex-officio-Prüfung durch die Gemeinschaftsgerichte (Mohr Paul Siebeck, Tübingen, 2008).

Schwartmann, Rolf \& Pabst, Heinz-Joachim, Umweltrecht (C.F. Müller, Heidelberg, 2011).

Wollenschläger, Ferdinand, Grundfreiheit ohne Markt. Die Herausbildung der Unionsbürgerschaft im unionsrechtlichen Freizügigkeitsregime (Mohr Siebeck, Tübingen, 2006). 


\section{Colaboración en obras colectivas}

Breuer, Rüdiger, Umweltschutzrecht, en Besonderes Verwaltungsrecht, 551-774 (13 ${ }^{\mathrm{a}}$ ed., Eberhard Schmidt-Aßmann \& Peter Badura, eds., Berlin, New York, Gruyter Lehrbuch, 2005).

\section{Revistas}

Calster, Geert van, Climate Change and Renewable Energy as a Super Trump for EU Trade Law: However All Essent Clear, 5 Renewable Energy Law and Policy, RELP, 1, 60-66 (2014). Disponible en: https://search.proquest.com/docview/1626 666771 ?accountid $=13250$

Fouquet, Dörte \& Guarrata, Angela, Judgment of $1^{\text {st }}$ July 2014 in Alands Vindkraft AB contra Energimyndigheten, 5 Renewable Energy Law and Policy, RELP, 1, 52-59 (2014). Disponible en: https://search.proquest.com/docview/1626666684?a ccountid $=13250$

Frenz, Walter, Windkraft vs. Artenschutz und Eigentümerbelange, 38 Natur und Recht, $\mathrm{NuR}, 4,251-257$ (2016).

Glinski, Carola, Kein Zwang zur Öffnung nationaler Fördersysteme für erneuerbare Energien zugunsten ausländischer Hersteller. Anmerkung zu EuGH, Urteil vom 1.7.2014, Rs. C-573/12 Alands Vindkraft AB gegen Energimyndigheten, 5 Europarecht, EuR, 567-575 (2014).

Glinski, Carola, Zu Viel Angst vor dem Europarecht?! Die "Energiewende" Zwischen Nationaler Politikhoheit Und Europäischem Binnenmarkt, 17 Zeitschrift für Europarechtliche Studien, ZEuS, 2, 235-255 (2014).

Grabmayr, Nora \& Kahles, Markus, Das Recht zur territorial begrenzten Förderung Erneuerbarer Energien, 5 EnergieRecht, ER, 183-187 (2014).

Kahle, Christian, Die beihilfenrechtliche Genehmigung des EEG 2014 durch die Europäische Kommission Eine kritische Würdigung, 23 Neue Zeitschrift für Verwaltungsrecht, $N V w Z, 1563-1566$ (2014).

Kreuter-Kirchhof, Charlotte, Die Rechtsmaßstäbe des EEG 2014 im Dienst von Klimaschutz, Kostenersparnis und Versorgungssicherheit, 21 Neue Zeitschrift für Verwaltungsrecht, $N V w Z, 1480-1486$ (2015).

Kröger, James, Das EEG 2014 im Lichte der Europäisierung des Rechts der Erneuerbaren Energien, 38 Natur und Recht, NuR, 2, 85-90 (2016).

Latzel, Clemens, Soziale Aspekte bei der Vergabe öffentlicher Aufträge nach der Richtlinie 2014/24/EU, 11 Neue Zeitschrift für Bau, NZBau, 673-681 (2014). Disponible en: http://www.jura.uni-muenchen.de/personen/1/latzel/schriftenverzeichnis/ cl2014-1.pdf

Ludwigs, Markus, Anmerkung zu EuGH, Urteil v. 01.07.2014, Rs. C-573/12 - Alands Vindkraft AB./.Energimyndigheten, 16 Europäische Zeitschrift für Wirtschaftsrecht, EuZW, 627-628 (2014).

Ludwigs, Markus, Die Förderung erneuerbarer Energien im doppelten Zangengriff 
des Unionsrechts, 06 Europäische Zeitschrift für Wirtschaftsrecht, EuZW, 201-202 (2014).

Ludwigs, Markus, EEG-Umlage und EU-Beihilferecht, Recht der erneuerbaren Energien, REE, 02, 65-76 (2014).

Ludwigs, Markus, Grenzen für eine nationale Energiepolitik im EU-Binnenmarkt, 11 Zeitschrift für das gesamte Energiewirtschaftsrecht, EnWZ, 483-488 (2013).

Scholtka, Boris \& Baumbach, Antje, Die Entwicklung des Energierechts im Jahr 2014, 13 Die Neue Juristische Wochenschrift, NJW, 911-916 (2015).

Wustlich, Guido, Das Erneuerbare-Energien-Gesetz 2014: Grundlegend neu-aber auch grundlegend anders?, 17 Neue Zeitschrift für Verwaltungsrecht, NVwZ, 1113-1122 (2014).

\section{Working papers y fichas técnicas}

Parlamento Europeo, Fichas técnicas sobre la Unión Europea, El mercado interior, 3.1. El mercado interior: marco general. Disponible en: http://www.europarl.europa. eu/atyourservice/es/displayFtu.html?ftuId=theme3.html

Steinbach, Armin, Renewable Energy and the Free Movement of Goods, 1-20 (Nuffield College Working Paper Series in Politics, Robert Brückmann Head, Policy Department, Eclareon, 2015). Disponible en: https://www.nuffield.ox.ac.uk/Research/ Politics\%20Group/Working\%20papers/Documents/Renewable\%20Energy\%20 and $\% 20$ the $\% 20$ Free $\% 20$ Movement $\% 20$ of $\% 20$ Goods.pdf

\section{Tratados y otros acuerdos internacionales}

Comunidad Económica Europea, Tratado Constitutivo de la Comunidad Económica Europea, Roma, 25 de marzo de 1957. Disponible en: http://ocw.uc3m.es/historiadel-derecho/historia-de-la-integracion-europea/tratados/Tratado_Cee.pdf/view

Organización de las Naciones Unidas, ONU, Convención de Naciones Unidas sobre cambio climático, París, 12 de diciembre de 2015. Disponible en: https://unfecc. int/files/meetings/paris_nov_2015/application/pdf/paris_agreement_spanish_.pdf

Unión Europea, Declaración de la Unión Europea de conformidad con el artículo 20, párrafo 3, del Acuerdo de París, L 282/4 Diario Oficial de la Unión Europea, 19 de octubre de 2016. Disponible en: http://eur-lex.europa.eu/legal-content/ES/ TXT/?uri=CELEX:22016A1019(01)

Unión Europea, Versión consolidada del Tratado constitutivo de la Comunidad Europea de la Energía Atómica, así como sus Anexos y Protocolos Luxemburgo, Oficina de Publicaciones de la Unión Europea (2010). doi:10.2860/52347. Disponible en: https:// europa.eu/european-union/sites/europaeu/files/docs/body/consolidated_version of_the_treaty_establishing_the_european_atomic_energy_community_es.pdf

Unión Europea, Versión consolidada del Tratado de Funcionamiento de la Unión Europea, C 83/47 Diario Oficial de la Unión Europea, 30 de marzo de 2010. Disponible en: https://www.boe.es/doue/2010/083/Z00047-00199.pdf 
Unión Europea, Versión consolidada del Tratado de la Unión Europea, C 83/13 Diario Oficial de la Unión Europea, 30 de marzo de 2010. http://www.boe.es/ doue/2010/083/Z00013-00046.pdf

Unión Europea, Carta Europea de los Derechos Fundamentales de la Unión Europea (2000/C 364/01), C 364/01 Diario Oficial de las Comunidades Europeas, 18 de diciembre de 2000. Disponible en: http://www.europarl.europa.eu/charter/pdf/ text_es.pdf

\section{Jurisprudencia internacional}

Comunidades Europeas, Tribunal de Justicia, sentencia de 1 de diciembre de 1965, asunto 16/65, C. Schwarze contra Einfuhr- und Vorratsstelle für Getreide und Futtermittel (Schwarze). Disponible en: http://eur-lex.europa.eu/legal-content/ES/ TXT/PDF/?uri=CELEX:61965CJ0016\&from=DE

Comunidades Europeas, Tribunal de Justicia, sentencia 10 de diciembre de 1968, asunto 7/68, Comisión de las Comunidades Europeas contra la República Italiana. Disponible en: http://curia.europa.eu/juris/showPdf.jsf?text=\&docid=87685\&pageIndex $=0 \&$ doclang $=\mathrm{ES} \&$ mode $=1$ st $\&$ dir $=\&$ occ $=$ first $\&$ part $=1 \&$ cid $=238292$

Comunidades Europeas, Tribunal de Justicia, sentencia de 11 de julio de 1974, asunto 8/74, Procureur du Roi y Benôt y Gustave Dassonville. Disponible en: http://eurlex.europa.eu/legal-content/ES/TXT/PDF/?uri=CELEX:61974CJ0008\&from=EN

Comunidades Europeas, Tribunal de Justicia, sentencia de 15 de diciembre de 1982, asunto 286/81, Oosthoek's Uitgeversmaatschappij BV. Disponible en: http://curia. europa.eu/juris/showPdf.jsf;jsessionid=9ea7d2dc30ddaee992aa639444f2812ae0fc 7558bcb1.e34KaxiLc3qMb40Rch0SaxuRbxn0?text $=\&$ docid=91544\&pageIndex $=$ $0 \&$ doclang $=$ es $\&$ mode $=1$ st $\&$ dir $=\&$ occ $=$ first $\&$ part $=1 \&$ cid $=132480$

European Court of Justice (second chamber), judgment of 8 November 1979, case 15/79, P. B. Groenveld B.V., Haarlem, and Produktschap voor Vee en Vlees [Cattle and Meat Board], Rijswijk, (Groenveld). Disponible en: http://curia.europa.eu/juris/ showPdf.jsf;jsessionid=9ea7d2dc30d675728081e2a9453da31d87064073be24.e34 KaxiLc3qMb40Rch0SaxyLb3r0?text $=\&$ docid $=90272$ \&pageIndex $=0 \&$ doclang $=$ EN\&mode $=1$ st \&dir $=\&$ occ $=$ first $\&$ part $=1 \&$ cid $=1019751$

Unión Europea, Tribunal de Justicia, sentencia 27 de abril de 1994, asunto C-393/92, Gemeente Almelo y otros Energiebedrijf IJsselmij NV (Almelo). Disponible en: http://curia.europa.eu/juris/showPdf.jsf?text $=\&$ docid $=98695 \&$ pageIndex $=0 \&$ doc lang $=$ ES\&mode $=1$ st $\&$ dir $=\&$ occ $=$ first $\&$ part $=1 \&$ cid $=896345$

Unión Europea, Tribunal de Justicia, sentencia de 13 de marzo de 2001, asunto C-379/98, PreussenElektra AG y Schleswag AG, con intervención de Windpark Reußenköge III GmbH y Land Schleswig-Holstein. Disponible en: http://curia.europa.eu/juris/ document/document.jsf?text $=\&$ docid $=45891 \&$ pageIndex $=0 \&$ doclang=ES\&mode $=1$ st\&dir $=\&$ occ $=$ first \&part $=1 \&$ cid $=319564$

Unión Europea, Tribunal de Justicia, sentencia de 12 de julio de 2001, asunto C-157/99, B.S.M. Smits, esposa de Geraets, y Stichting Ziekenfonds VGZ y entre H.T.M. Peerbooms y Stichting CZ Groep Zorgverzekeringen. Disponible en: http://curia. 
europa.eu/juris/document/document.jsf?text $=\&$ docid $=46529 \&$ pageIndex $=0 \&$ doc lang $=$ ES\&mode $=1$ st \& dir $=\&$ occ $=$ first $\&$ part $=1 \& \operatorname{cid}=763671$

Unión Europea, Tribunal de Justicia, sentencia de 13 de mayo de 2003, asunto C-385/99, V.G. Müller-Fauré y Onderlinge Waarborgmaatschappij OZ Zorgverzekeringen $U A$, y entre E.E.M. van Riet y Onderlinge Waarborgmaatschappij ZAO Zorgverzekeringen. Disponible en: http://curia.europa.eu/juris/document/document.jsf?t ext $=\&$ docid $=48278 \&$ pageIndex $=0 \&$ doclang $=E S \&$ mode $=1$ st \&dir $=\& o c c=$ first $\& p$ art $=1 \&$ cid $=790132$

Unión Europea, Tribunal de Justicia (sala tercera), sentencia de 2 de diciembre de 2004, asunto C-41/02, Comisión de las Comunidades Europeas, contra Reino de los Países Bajos. Disponible en: http://curia.europa.eu/juris/document/document. jsf?text $=$ asunto $\% 2 \mathrm{BC}-41 \% 252 \mathrm{~F} 02 \&$ docid $=49727 \&$ pageIndex $=0 \&$ doclang $=\mathrm{ES} \&$ mode $=$ req $\&$ dir $=\&$ occ $=$ first $\&$ part $=1 \&$ cid $=1073636 \#$ ctx 1

Unión Europea, Tribunal de Justicia, sentencia de 14 de diciembre de 2004, asunto C-309/02, Radlberger Getränkegesellschaft mbH \& Co. Disponible en: http://curia. europa.eu/juris/document/document.jsf;jsessionid=9ea7d2dc30d64fe96b007d1f4 663adf69128a399d768.e34KaxiLc3qMb40Rch0SaxyLbN50?text $=$ \&docid $=4976$ $1 \&$ pageIndex $=0 \&$ doclang $=\mathrm{ES} \&$ mode $=1$ st\&dir $=\&$ occ $=$ first $\&$ part $=1 \&$ cid $=921859$

Unión Europea, Tribunal de Justicia (gran sala), sentencia de 5 de junio de 2007, asunto C-170/04, Klas Rosengren, y otros y Riksåklagaren. Disponible en: http://curia. europa.eu/juris/document/document.jsf?text=asunto\%2BC-41\%252F02\&docid= 63050\&pageIndex $=0 \&$ doclang $=E S \&$ mode $=$ req \&dir $=\&$ occ $=$ first $\&$ part $=1 \&$ cid $=1$ 073636\#ctx1

Unión Europea, Tribunal de Justicia, Conclusiones de la abogada general Verica Trstenjak, presentadas el 17 de julio de 2008, Asunto C-205/07, Procedimiento penal contra Lodewijk Gysbrechts y Santurel Inter BVBA [Petición de decisión prejudicial planteada por el Hof van Beroep te Gent (Bélgica)]. Disponible en: http://eur-lex. europa.eu/legal-content/ES/TXT/HTML/?uri=CELEX:62007CC0205\&from=DE

Unión Europea, Tribunal de Justicia (gran sala), sentencia de 5 de octubre de 2010, asunto C-512/08, Comisión Europea contra República Francesa, apoyada por: Reino de España, República de Finlandia, Reino Unido de Gran Bretaña e Irlanda del Norte. Disponible en: http://curia.europa.eu/juris/document/document.jsf?tex $\mathrm{t}=\&$ docid $=81397 \&$ pageIndex $=0 \&$ doclang $=\mathrm{ES} \&$ mode $=1$ st\&dir $=\&$ occ $=$ first \&part $=1 \& \mathrm{cid}=780963$

Unión Europea, Tribunal de Justicia (sala quinta), sentencia de 6 de octubre de 2011, asunto C-443/10, Philippe Bonnarde y Agence de Services et de Paiement. Disponible en: http://eur-lex.europa.eu/legal-content/ES/TXT/HTML/?uri=CELEX:62 010CJ0443\&from=ES

Unión Europea, Tribunal de Justicia, asunto C-573/12, Alands Vindkraft AB contra Energimyndigheten, Conclusiones del Abogado General Yves Bot, presentadas el 28 de enero de 2014. Disponible en: http://eur-lex.europa.eu/legal-content/ES/TX $\mathrm{T} /$ ?uri=CELEX\%3A62012CC0573\#Footnote30

Unión Europea, Tribunal de Justicia (gran sala), sentencia de 1 de julio de 2014, asunto C-573/12, Alands Vindkraft AB contra Energimyndigheten, Petición de decisión prejudicial: Förvaltningsrätten i Linköping - Suecia. Disponible en: http://curia. 
europa.eu/juris/liste.jsf?language=es\&num $=\mathrm{C}-573 / 12$

Unión Europea, Tribunal de Justicia (sala segunda), sentencia de 17 de marzo de 2016, asunto C-472/14, Canadian Oil Company Sweden AB, Anders Rantén y Riksåklagaren. Disponible en: http://curia.europa.eu/juris/document/document.jsf?docid= $175163 \&$ mode $=$ req \& pageIndex $=1 \& \operatorname{dir}=\&$ occ $=$ first $\&$ part $=1 \&$ text $=\mathrm{C} \% 25 \mathrm{E} 2 \% 258$ $0 \% 2591472 \% 252 \mathrm{~F} 14 \&$ doclang=ES\&cid $=69553 \#$ ctx 1

Unión Europea, Tribunal de Justicia (sala segunda), sentencia de 22 de septiembre de 2016, asunto C-525/14, Comisión Europea contra República Checa, apoyada por la República Francesa. Disponible en: http://curia.europa.eu/juris/document/ document.jsf?text=restricci $\% 25 \mathrm{C} 3 \% 25 \mathrm{~B} 3 \mathrm{n} \% 2 \mathrm{Bcuantitativa} \% 2 \mathrm{Ba} \% 2 \mathrm{Bla} \% 2 \mathrm{Bimp}$ ortaci $\% 25 \mathrm{C} 3 \% 25 \mathrm{~B} 3 \mathrm{n} \&$ docid $=183704 \&$ pageIndex $=0 \&$ doclang $=$ ES\&mode $=$ req $\& d$ ir $=\&$ occ $=$ first\&part $=1 \&$ cid $=72782 \#$ ctx 1

Unión Europea, Tribunal de Justicia (sala segunda), sentencia de 29 de septiembre de 2016, asunto C-492/14, Essent Belgium NV y Vlaams Gewest, Inter-Energa, IVEG, Infrax West, Provinciale Brabantse Energiemaatschappij CVBA (PBE), Vlaamse Regulator van de Elektriciteits- en Gasmarkt (VREG). Disponible en: http://curia. europa.eu/juris/document/document.jsf;jsessionid=9ea7d0f130d5c4af334e98084 a91bd7dfcd9992e1102.e34KaxiLc3eQc40LaxqMbN4PaxiLe0?text=\&docid=1839 $25 \&$ pageIndex $=0 \&$ doclang $=E S \&$ mode $=1$ st $\&$ dir $=\&$ occ $=$ first $\&$ part $=1 \&$ cid $=197617$

Unión Europea, Tribunal de Justicia (sala primera), sentencia de 19 de octubre de 2016, asunto C-148/15, Deutsche Parkinson Vereinigung eV y Zentrale zur Bekämpfung unlauteren Wettbewerbs eV. Disponible en: http://curia.europa.eu/juris/document/ document.jsf?text $=\% 2$ Brestricciones $\% 2 \mathrm{~B}$ cuantitativas $\% 2 \mathrm{Ba} \% 2 \mathrm{Bla} \% 2 \mathrm{Bimportac}$ i\%25C3\%25B3n\%2Bentre\%2Blos\%2BEstados\%2Bmiembros\&docid=184671\&pa geIndex $=0 \&$ doclang $=E S \&$ mode $=$ req $\&$ dir $=\& o c c=$ first $\&$ part $=1 \&$ cid $=1041198 \#$ ctx 1

Unión Europea, Tribunal de Justicia (sala primera), sentencia de 27 de abril de 2017, asunto C-672/15, Noria Distribution SARL. Disponible en: http://curia.europa.eu/ juris/document/document.jsf?text=prohibici $\% 25 \mathrm{C} 3 \% 25 \mathrm{~B} 3 \mathrm{n} \% 2 \mathrm{Bde} \% 2 \mathrm{Brestriccio}$ nes $\% 2 B$ cuantitativas \&docid $=190163 \&$ pageIndex $=0 \&$ doclang $=E S \&$ mode $=$ req $\& d$ ir $=\&$ occ $=$ first $\&$ part $=1 \&$ cid $=1037895 \#$ ctx 1

\section{Resoluciones u otros documentos internacionales}

Comunidad Europea, Comisión Europea, Guía para la interpretación y aplicación de los artículos 28 a 30 del Tratado CE (Bruselas, Comisión Europea, DG de Mercado Interior, enero de 2001). Disponible en: http://www.ppl.nl/passcat. php?sig=EU_Guide-Art-28-30_s.pdf

Unión Europea, Comisión Europea, Anexo. Medidas para impulsar la transición hacia una energía limpia de la Comunicación de la Comisión al Parlamento Europeo, al Consejo, al Comité Económico y Social Europeo, al Comité de las Regiones y al Banco Europeo de Inversiones Energía limpia para todos los europeos. Disponible en: http://eur-lex.europa.eu/legal-content/ES/TXT/HTML/?uri=CELEX:52016DC 0860(01)\&from $=\mathrm{ES}$

Unión Europea, Comisión Europea, Comunicación de la Comisión al Parlamento Europeo, al Consejo, al Comité Económico y Social Europeo, al Comité de las Regiones y 
al Banco Europeo de Inversiones. Energía limpia para todos los europeos, Bruselas, 30 de noviembre de 2016 COM (2016) 860 final. Disponible en: http://eur-lex.europa. eu/legal-content/ES/TXT/HTML/?uri=CELEX:52016DC0860(01)\&from=ES

Unión Europea, Comisión Europea, Comunicación de la Comisión al Parlamento Europeo, al Consejo, al Comité Económico y Social Europeo y al Comité de las Regiones. Un marco estratégico en materia de clima y energía para el período 2020-2030, COM/2014/015 final, 22 de enero de 2014. Disponible en: http://eur-lex. europa.eu/legal-content/ES/TXT/HTML/?uri=CELEX:52014DC0015\&from=DE

Unión Europea, Comisión Europea, Dirección C, Política reglamentaria, de la Dirección General de Empresa e Industria, Libre circulación de mercancías, Guía para la aplicación de las disposiciones del Tratado que rigen la libre circulación de mercancias. Disponible en: http://bookshop.europa.eu/es/libre-circulaci-n-demercanc-as-pbNB3109160/

Unión Europea, Comisión Europea, Informe de la Comisión al Parlamento Europeo, al Consejo, al Comité Económico y Social Europeo y al Comité de las Regiones. Informe de situación en materia de energías renovables, COM (2017) 57 final, 1 de febrero de 2017. Disponible en: http://eur-lex.europa.eu/legal-content/ES/ TXT/?uri=CELEX\%3A52017DC0057

Unión Europea, Comunicación de la Comisión de la Unión Europea, Directrices sobre ayudas estatales en materia de protección del medio ambiente y energía 2014-2020, (2014/C 200/01), C 200/01 Diario Oficial de la Unión Europea, 28 de junio de 2014. Disponible en: http://eur-lex.europa.eu/legal-content/ES/TXT/HTML/?uri=CELE X:52014XC0628(01)\&from=DE

Unión Europea, Información básica sobre la Unión Europea, Instituciones y organismos de la UE, Tribunal de Justicia de la Unión Europea (TJUE). Disponible en: https:// europa.eu/european-union/about-eu/institutions-bodies/court-justice_es

\section{Normatividad internacional}

Parlamento Europeo y Consejo Europeo, Directiva 2009/28/CE, de 23 de abril de 2009, relativa al fomento del uso de energía procedente de fuentes renovables y por la que se modifican y se derogan las Directivas 2001/77/CE y 2003/30/CE (Texto pertinente a efectos del EEE), L 140/16 Diario Oficial de la Unión Europea, 5 de junio de 2009. Disponible en: https://www.boe.es/doue/2009/140/L00016-00062.pdf 
